\title{
Prospecting for a quinoline containing selenium for comorbidities depression and memory impairment induced by restriction stress in mice
}

\author{
Renata L. de Oliveira ${ }^{1}$. Guilherme T. Voss ${ }^{1} \cdot$ Karline da C. Rodrigues ${ }^{1} \cdot$ Mikaela P. Pinz $^{1}$. Julia V. Biondi ${ }^{1}$. \\ Nicole P. Becker ${ }^{1} \cdot$ Eduardo Blodorn $^{2}$ - William B. Domingues ${ }^{2} \cdot$ Allya Larroza $^{3} \cdot$ Vinícius F. Campos $^{2}$ - Diego Alves ${ }^{3}$. \\ Ethel A. Wilhelm ${ }^{1} \cdot$ Cristiane Luchese $^{1}($ i)
}

Received: 24 June 2021 / Accepted: 29 November 2021 / Published online: 11 January 2022

(c) The Author(s), under exclusive licence to Springer-Verlag GmbH Germany, part of Springer Nature 2021

\begin{abstract}
Rationale Depression is often associated with memory impairment, a clinical feature of Alzheimer's disease (AD), but no effective treatment is available. 7-Chloro-4-(phenylselanyl) quinoline (4-PSQ) has been studied in experimental models of diseases that affect the central nervous system.

Objectives The pharmacological activity of 4-PSQ in depressive-like behavior associated with memory impairment induced by acute restraint stress (ARS) in male Swiss mice was evaluated.

Methods ARS is an unavoidable stress model that was applied for a period of $240 \mathrm{~min}$. Ten minutes after ARS, animals were intragastrically treated with canola oil $(10 \mathrm{ml} / \mathrm{kg})$ or 4-PSQ $(10 \mathrm{mg} / \mathrm{kg})$ or positive controls (paroxetine or donepezil) $(10 \mathrm{mg} / \mathrm{kg})$. Then, after $30 \mathrm{~min}$, mice were submitted to behavioral tests. Corticosterone levels were evaluated in plasma and oxidative stress parameters; monoamine oxidase (MAO)-A and MAO -B isoform activity; mRNA expression levels of kappa nuclear factor B (NF- $\mathrm{kB}$ ); interleukin (IL)-1 $\beta$, IL-18, and IL-33; phosphatidylinositol-se-kinase (PI3K); protein kinase B (AKT2), as well as acetylcholinesterase activity were evaluated in the prefrontal cortex and hippocampus.

Results 4-PSQ attenuated the depressive-like behavior, self-care, and memory impairment caused by ARS. Based on the evidence, we believe that effects of 4-PSQ may be associated, at least in part, with the attenuation of HPA axis activation, attenuation of alterations in the monoaminergic system, modulation of oxidative stress, reestablishment of AChE activity, modulation of the PI3K/AKT2 pathway, and reduction of neuroinflammation.

Conclusions These results suggested that 4-PSQ exhibited an antidepressant-like effect and attenuated the memory impairment induced by ARS, and it is a promising molecule to treat these comorbidities.
\end{abstract}

Keywords Corticosterone $\cdot$ Alzheimer's disease $\cdot$ Oxidative stress $\cdot$ Neuroinflammation $\cdot$ Neuroplasticity $\cdot$ Acute restraint stress $\cdot$ Central nervous system

\begin{tabular}{llll}
\multicolumn{2}{l}{ Abbreviations } & CNS & Central nervous system \\
4-PSQ & 7-Chloro-4-(phenylselanyl) quinoline & NF-kB & Kappa nuclear factor B \\
AD & Alzheimer's disease & PI3K & Phosphatidylinositol-3-kinase \\
ARS & Acute restraint stress & AKT2 & Protein kinase B-2
\end{tabular}

Ethel A. Wilhelm

ethelwilhelm@yahoo.com.br

Cristiane Luchese

cristiane_luchese@yahoo.com.br

1 Programa de Pós-Graduação Em Bioquímica E Bioprospecção (PPGBBio), Laboratório de Pesquisa Em Farmacologia Bioquímica (LaFarBio), Centro de Ciências Químicas, Farmacêuticas E de Alimentos, Universidade Federal de Pelotas, Pelotas, RS CEP 96010-900, Brazil
2 Laboratório de Genômica Estrutural, Programa de Pós-Graduação Em Biotecnologia, Universidade Federal de Pelotas, Pelotas, RS, Brazil

3 Laboratório de Síntese Orgânica Limpa (LaSOL), Centro de Ciências Químicas, Farmacêuticas E de Alimentos, Programa de Pós-Graduação Em Química, Universidade Federal de Pelotas, Pelotas, RS, Brazil 


$\begin{array}{ll}\text { AChE } & \text { Acetylcholinesterase } \\ \text { Ach } & \text { Acetylcholine } \\ \text { AcSCh } & \text { Acetylthiocholine } \\ \text { HPA } & \text { Hypothalamic-pituitary-adrenal } \\ \text { OFT } & \text { Open field test } \\ \text { SPT } & \text { Splash test } \\ \text { TST } & \text { Tail suspension test } \\ \text { FST } & \text { Forced swimming test } \\ \text { RS } & \text { Reactive species } \\ \text { TBARS } & \text { Thiobarbituric acid reactive species } \\ \text { SOD } & \text { Superoxide dismutase } \\ \text { GPx } & \text { Glutathione peroxidase } \\ \text { GR } & \text { Glutathione reductase } \\ \text { S1 } & \text { Supernatant fractions } \\ \text { MDA } & \text { Malondialdehyde } \\ \text { GSH } & \text { Glutathione } \\ \text { GSSH } & \text { Oxidized glutathione } \\ \text { NADPH } & \text { Nicotinamide adenine dinucleotide } \\ & \text { phosphate } \\ \text { Pi } & \text { Inorganic phosphate } \\ \text { NMR } & \text { Nuclear magnetic resonance } \\ \text { DCHF-DA } & \text { Dichlorofluorescein diacetate } \\ \text { DCF } & \text { Fluorescent dichlorofluorescein } \\ \text { ANOVA } & \text { Analysis of variance } \\ \text { COVID-19 } & \text { Coronavirus disease } \\ \text { SARS-CoV-2 } & \text { Severe acute respiratory syndrome corona- } \\ & \text { virus 2 } \\ \text { MAO } & \text { Monoamine oxidase } \\ \text { IL } & \text { Interleukin } \\ \text { BBB } & \text { Blood-brain barrier } \\ \text { ORT } & \text { Object recognition task } \\ \text { STM } & \text { Short-term memory } \\ \text { LTM } & \text { Long-term memory } \\ \text { MP } & \text { Mitochondrial pellet } \\ & \end{array}$

\section{Introduction}

Depression is a neuropsychiatric disease whose main characteristics are persistent depressed mood and anhedonia (Anisman et al. 2008). According to the World Health Organization (2021), about 264 million individuals are affected by this disorder (Miret et al. 2013). Stress has been the main factor associated with the development of depression, promoting an imbalance in body homeostasis, resulting in physiological, pathological, and/or cognitive changes that mainly affect the central nervous system (CNS) (Linthorst and Reul 2008; Mariotti 2015). In addition, relatively high rates of stress $(81.9 \%)$ are associated with the impact of the Coronavirus 2019 disease pandemic (COVID-19), affecting the mental health of the population (Xiong et al. 2020).

In parallel, depression can develop as a consequence of some conditions, such as Alzheimer's disease (AD) (Heun et al. 2013). In fact, stress (mainly psychosocial) and depression are usually accompanied by memory impairment, which is one of the most important clinical characteristics of patients with AD (Marazziti et al. 2010; Murrough et al. 2011). In this context, depression is considered one of the most prevalent comorbidities in $\mathrm{AD}$, being responsible for affecting about $50 \%$ of patients, and associated with a great social, medical, and economic burden (Chi et al. 2014; Romano et al. 2015). An animal model of acute restraint stress (ARS) is commonly used to induce behavior related to depression in rodents, which can induce behavioral and neurochemical changes similar to those found in patients with this disorder (Klenerová et al. 2007). In addition, studies report that ARS may cause memory impairment in rodents and can be useful to assess the comorbidities of depression and memory impairment/AD (Baker and Kim 2002; Walesiuk et al. 2005; Nagata et al. 2009; Li et al. 2012). Indeed, molecular mechanisms related to the depression and memory impairment/AD dyad are considered complex and still poorly understood. Under these circumstances, research to elucidate the mechanisms involved in depression and memory impairment/DA has attracted the researchers' interest.

It has been shown that in patients with depression and memory impairment/AD, there is a deregulation of the hypothalamic-pituitary-adrenal (HPA) axis, promoting an increase in the glucocorticoid levels, such as cortisol (corticosterone in rodents) (Sierksma et al. 2010). Other common neuronal pathways in depression and memory impairment/AD include dysfunction in the monoaminergic system, oxidative stress, neuroinflammatory processes, and altered neuroplasticity (Caraci et al. 2010; Sierksma et al. 2010; Maes et al. 2011). In addition, some cell signaling molecules are involved in the progression of depression associated with memory impairment/AD. Among them is the phosphatidylinositol-3-kinase (PI3K)/protein kinase B (AKT) pathway that when activated is responsible for regulating neuronal survival and neuroplasticity, which are important functions for the comorbidity in question (Li et al. 2015a). In parallel, the nuclear factor kappa $\mathrm{B}(\mathrm{NF}-\mathrm{\kappa B})$ can be activated in the face of different stimuli, such as inflammatory and stress responses, thus regulating the expression of inflammatory cytokines (Oeckinghaus and Ghosh 2009). Therefore, it is highly relevant to evaluate these mechanisms, as they can act as potential targets in the development of a treatment for depression associated with memory impairment/AD.

Given the multifactorial etiology of comorbidities, depression, and memory impairment/AD, besides the adverse effects of using combined drugs, multifunctional molecules with two or more complementary biological activities may represent an important advance for the treatment of these conditions. In this context, 7-chloro-4(phenylselanyl) quinoline (4-PSQ), a quinoline functionalized with an organoselenium group, has been outstanding, 
given that it demonstrated several pharmacological effects. Previously, 4-PSQ showed an effect on disorders that affect the CNS in preclinical models, by reducing neuropsychiatric symptoms, such as anxiety and depression (Reis et al. 2017; Paltian et al. 2020; Rodrigues et al. 2021), prevention of memory impairment, and cognitive deficit (Duarte et al. 2017; Pinz et al. 2018; Barth et al. 2019), as well as attenuation of AD comorbidity and anxiety in mice (Pinz et al. 2018). Additionally, the anti-AD effect of 4-PSQ in mice was evidenced (Pinz et al. 2018), as well as its action in improving the memory of aged rats (Barth et al. 2019). It should also be noted that the mechanisms related to the effects of 4-PSQ include its antioxidant action (Pinz et al. 2016; Duarte et al. 2017; Vogt et al. 2018; Luchese et al. 2020), anti-inflammatory effect (Pinz et al. 2016; Silva et al. 2017), as well as its ability to modulate the serotonergic, nitrergic, glutamatergic, and cholinergic systems, evidencing the characteristic multi-target of this molecule (Pinz et al. 2016, 2018; Reis et al. 2017; Silva et al. 2017; Vogt et al. 2018; Barth et al. 2019; Paltian et al. 2020). Furthermore, this compound has already demonstrated the absence of toxicity in mice (Reis et al. 2017; Salgueiro et al. 2017), modulation of synaptic plasticity through increased levels of neural cell adhesion molecules, and levels of polysialyltransferase in brain structures of elderly rats (Barth et al. 2019), besides reducing glutamate uptake in the brain of mice (Reis et al. 2017). Bearing in mind that this molecule presents various promising activities, the objective of this study was to determine the pharmacological activity of 4-PSQ in the dyad of depression and memory impairment induced by ARS in mice, as well as the mechanisms involved in these processes.

\section{Materials and methods}

\section{Animals and ethical approval}

The experiments were conducted using male Swiss mice (25-35 g). Animals were maintained in standard cages placed in rooms at a controlled temperature $\left(22 \pm 2{ }^{\circ} \mathrm{C}\right)$ and humidity $(75 \pm 5 \%)$, with free access to water and food, under a $12 \mathrm{~h} \mathrm{light/dark} \mathrm{cycle} \mathrm{(with} \mathrm{lights} \mathrm{on} \mathrm{at} \mathrm{7:00}$ a.m.). The experiments were approved by the Committee on Care and Use of Experimental Animal Resources, Federal University of Pelotas, Brazil (CEEA 28,008-2019), following the National Institutes of Health guide for the care and use of laboratory animals (NIH Publications No. 8023, revised 1978). All behavioral tests were conducted during the light period of the light/dark cycle. Every effort was made to minimize the number of animals used and their discomfort.

\section{Drugs}

4-PSQ (Fig. 1a) was prepared and characterized in our laboratory using the method previously described by Duarte et al. (2017). Analysis of the ${ }^{1} \mathrm{H}$ nuclear magnetic resonance (NMR) and ${ }^{13} \mathrm{C}$ NMR spectra showed analytical and spectroscopic data in full agreement with its assigned structure. The chemical purity of 4-PSQ (99.9\%) was determined by gas chromatography-mass spectrometry. Paroxetine (antidepressant, selective serotonin reuptake inhibitor) and donepezil (acetylcholinesterase inhibitor, used in the treatment of AD) were used as positive controls. All drugs were diluted in canola oil and administered at a constant volume of $10 \mathrm{ml} / \mathrm{kg}$ of body weight. All other chemicals were of analytical grade and obtained from standard commercial suppliers.

\section{Acute restraint stress procedure}

The animals were submitted to physical restraint as previously reported by Sousa et al. (2018). Mice were subjected to immobilization for 240 min using an individual rodent restraint device made of fenestrated Plexiglas, restraining physical movement. During the period of exposure to stress, the animals were deprived of water and food. Behavioral tests were performed $40 \mathrm{~min}$ after removal of the animals from the restraint in order to avoid non-specific motor effects because of restricted movement.

\section{Experimental design}

In the experimental protocol (Fig. 1b), the animals were randomly divided into six experimental groups (seven animals/ group): (I) control (non-stressed), (II) 4-PSQ (non-stressed), (III) control-ARS, (IV) ARS + 4-PSQ, (V) ARS + Paroxetine and (VI) ARS + Donepezil. In stressed animals, the ARS protocol was performed for $240 \mathrm{~min}$ and non-stressed animals continued to have access to water and food during the same period. After the restriction, stressed animals were kept under standard environmental conditions $\left(22 \pm 1{ }^{\circ} \mathrm{C}\right)$ with free access to water and food for $10 \mathrm{~min}$ to readjust movements. Afterwards, animals in groups I and III received canola oil (vehicle of the compounds, $10 \mathrm{ml} / \mathrm{kg}$, intragastrically (i.g.)), groups II and IV received 4-PSQ (10 mg/kg, i.g.), group $\mathrm{V}$ received paroxetine (positive control, $10 \mathrm{mg} /$ $\mathrm{kg}$, i.g.), and group VI received donepezil (positive control, $10 \mathrm{mg} / \mathrm{kg}$, i.g.). After $30 \mathrm{~min}$ of treatments, the animals were subjected to behavioral tasks: open field test (OFT), splash test (SPT), tail suspension test (TST), forced swimming test (FST), and Y-maze task. All behavioral tests were evaluated in independent groups of animals. After the behavioral assessment, the mice were anesthetized (isoflurane inhalation) before blood collection by cardiac puncture (Parasuraman et al. 2010). Subsequently, the animals were euthanized 


\section{a Chemical structure of 4-PSQ}<smiles>Clc1ccc2c([Se]c3ccccc3)ccnc2c1</smiles>

\section{b Experimental protocol}

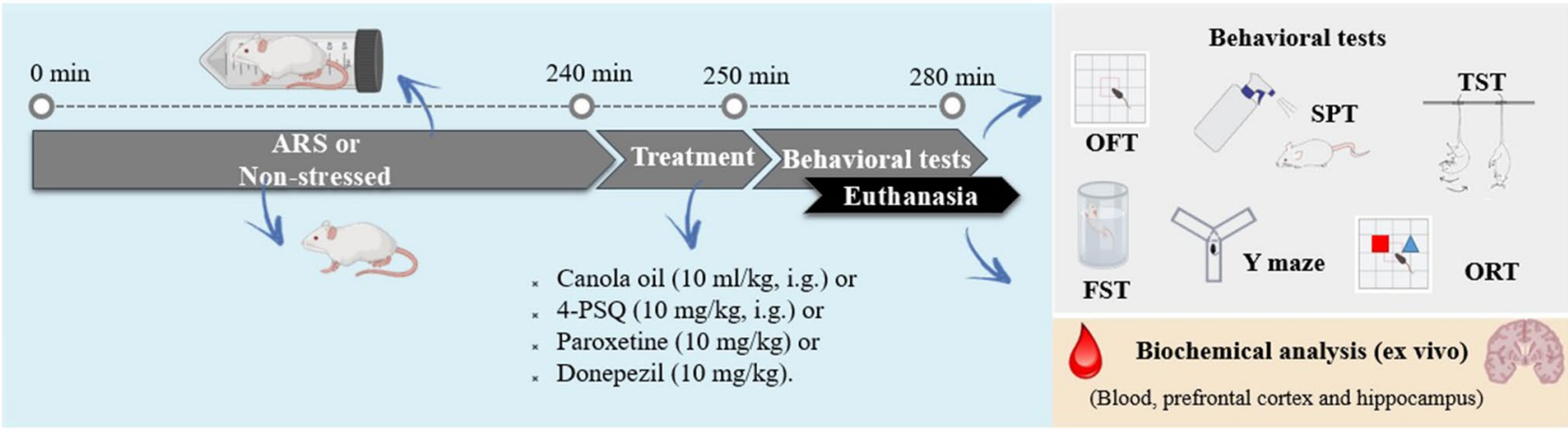

Fig. 1 a Chemical structure of 7-chloro-4-(phenylselanyl) quinoline (4-PSQ) and b Scheme of the experimental protocol. Initially, the stressed animals were subjected to acute restraint stress (ARS) for $240 \mathrm{~min}$ and the non-stressed animals continued to have access to water and feed during the same period. Then, the stressed animals were removed for $10 \mathrm{~min}$ to readjust their movements, and then all received canola oil (10 ml/kg) or 4-PSQ $(10 \mathrm{mg} / \mathrm{kg}$, i.g.) or paroxetine

to remove brain structures, prefrontal cortex, and hippocampus, for biochemical analysis. The dose, vehicle, and administration time/route of 4-PSQ treatment were based on previous studies (Pesarico et al. 2015; Sousa et al. 2018; Casaril et al. 2019; Domingues et al. 2019; Martini et al. 2019; Pregardier Klann et al. 2020), in order to minimize the number of animals, a dose-response curve was not used in the present study.

\section{Behavioral tests}

All behavioral tests were scored by a blinded observer; i.e., the researcher does not know to which treatment the mouse was submitted.

\section{OFT}

OFT evaluated the general locomotor and exploratory behavior of mice in order to exclude any psychomotor alterations (Walsh and Cummins 1976). The open field was made of plywood and surrounded by $30 \mathrm{~cm}$-high walls. Nine squares (3 rows of 3) marked by masking tape, divided the open field into $45 \mathrm{~cm}$ long and $45 \mathrm{~cm}$ wide sections. Thirty minutes
(10 mg/kg, i.g.) or donepezil (10 mg/kg, i.g.) intragastrically (i.g.). After 30 min of treatment, the animals were subjected to behavioral tests: open field test (OFT), splash test (SPT), tail suspension test (TST), forced swimming test (FST), Y-maze task, and object recognition test (ORT). After the behavioral assessment, the animals were sacrificed for biochemical analyses (ex vivo)

after treatments, each animal was placed at the center of the open field and observed for 4 min to record the locomotor (number of segments crossed with the four paws) and exploratory (number of rearings on the hind limbs) activities.

\section{SPT}

The grooming behavior of mice was observed as a measurement of motivational and self-care activities, which are considered to be reduced in depressive patients. This method consists of spraying a $10 \%$ sucrose solution on the back of mice in their home cage. The sucrose solution dirties the coat and induces grooming behavior (nose/face, head, and body) due to its viscosity. The total grooming time is assessed over a period of $5 \mathrm{~min}$ (Freitas et al. 2013).

\section{TST}

TST was conducted as described by Steru et al. (1985). Mice were suspended $50 \mathrm{~cm}$ above the ground by an adhesive tape placed approximately $1 \mathrm{~cm}$ from the tip of the animal's tail. Mice were considered immobile only when they hung passively and completely motionless. Immobility time was 
manually recorded during a 6-min period (Kaster et al. 2005).

\section{FST}

FST was conducted using the method described by Porsolt et al. (1977). In this test, mice were individually forced to swim in an open cylindrical container $(10 \mathrm{~cm}$ in diameter and $25 \mathrm{~cm}$ in height), containing $19 \mathrm{~cm}$ of water at $25 \pm 1{ }^{\circ} \mathrm{C}$. The duration of immobility was scored during a 6-min period (Kaster et al. 2005). Each mouse was considered immobile when floating motionless or making only those movements necessary to keep its head above the water.

Y-maze task The Y-maze task was performed as described by Sarter et al. (1988) and it was used as a measure of working memory. The Y-maze apparatus consisted of a threearmed horizontal maze $(40 \mathrm{~cm}$ long and $3 \mathrm{~cm}$ wide with walls $12 \mathrm{~cm}$ high) in which the three arms at $120^{\circ}$ angles to each other radiate out from a central point. Briefly, mice were initially placed within one arm (A), and the arm entry sequence (e.g., ABCCAB, where letters indicate arm codes) and the number of arm entries were recorded in an 8-min period. Alternation was determined from successive entries into the three arms on overlapping triplet sets in which three different arms are entered. An actual alternation was defined as entries into all three arms consecutively (i.e., $\mathrm{ABC}, \mathrm{BCA}$, or $\mathrm{CAB}$ but not $\mathrm{ABA})$. An entry was defined as placing all four paws within the boundaries of the arm.

Object recognition task Object recognition task (ORT) was used to assess the short-term (STM) and long-term (LTM) memories of mice in an open field apparatus, according to Lueptow (2017) with some modifications. Initially, the animals were submitted to a habituation session in the absence of objects, for 10 min (day 1). Subsequently, four objects were used: A1, A2, B, and C. Each object had the following color patterns: blue, red, and yellow. All objects were made of plastic, measuring $10 \times 10 \mathrm{~cm}$ (length $\times$ height). On the second day of the experimental protocol, the ARS and treatments were performed (according to item 2.4) before the training session. During the training, $24 \mathrm{~h}$ after the habituation session (day 2), the animals were placed in the arena containing two identical objects (objects A1 and A2) for 5 min. Object exploration was defined as sniffing, touching the object with the nose, or pointing the nose towards the object from a distance shorter than $2 \mathrm{~cm}$. The STM of mice was evaluated $1 \mathrm{~h}$ after training in the presence of a familiar object (A1) and a new object (B), and the total time spent in exploring each object was determined for $5 \mathrm{~min}$ to measure the learning and recognition memory. The LTM was performed $24 \mathrm{~h}$ after training (day 3 ), where mice were placed to explore a familiar object (A1) and a new object (C) for $5 \mathrm{~min}$ and the total time spent in exploring each object was determined. In order to analyze the cognitive performance, the exploratory preference was calculated and data were expressed as percentage as follows: training $=(\mathrm{A} 2 /$ $(\mathrm{A} 1+\mathrm{A} 2)) \times 100 ; \mathrm{STM}=(\mathrm{B} /(\mathrm{A} 1+\mathrm{B})) \times 100 ; \mathrm{LTM}=(\mathrm{C} /$ $(\mathrm{A} 1+\mathrm{C})) \times 100)$.

\section{Biochemical analysis}

\section{Tissue processing}

Mice were anesthetized with isoflurane and blood samples collected from the heart ventricle, using heparin as an anticoagulant. Blood samples were centrifuged at $900 \times g$ for 15 min to obtain plasma. Plasma was used to determine corticosterone levels. Prefrontal cortex and hippocampus were removed and immediately homogenized in cold $50 \mathrm{mM}$ Tris-HCl, $\mathrm{pH} 7.4$ (1/10, weight (w)/volume(v)). The homogenates were centrifuged at $900 \times g$ at $4{ }^{\circ} \mathrm{C}$ for $10 \mathrm{~min}$ and supernatant fractions (S1) were used to determine reactive species (RS) levels, thiobarbituric acid reactive species (TBARS) levels, and activity of superoxide dismutase (SOD), glutathione peroxidase (GPx), and glutathione reductase (GR). For the determination of the activity of acetylcholinesterase $(\mathrm{AChE})$, brain structures of mice were homogenized in $0.25 \mathrm{M}$ sucrose buffer $(1 / 10, \mathrm{w} / \mathrm{v})$ and centrifuged at $900 \times g$ at $4{ }^{\circ} \mathrm{C}$ for $10 \mathrm{~min}$. Additionally, the prefrontal cortex and hippocampus were separated for mRNA extraction and expression of NF-kB, IL-1 $\beta$, IL-18, IL-33, $\mathrm{PI} 3 \mathrm{~K}$, and AKT2. For this, the samples were immediately processed and adequately stored $\left(-80^{\circ} \mathrm{C}\right)$ until the mRNA expression levels were evaluated.

Measuring the activity of the monoamine oxidase (MAO) enzyme preparation of brain mitochondria was performed. For this, the prefrontal cortex and the hippocampus were removed and homogenized with an isolation medium $\left(\mathrm{Na}_{2} \mathrm{PO}_{4} / \mathrm{KH}_{2} \mathrm{PO}_{4}\right.$ isotonized with sucrose, $\mathrm{pH}$ 7.4) (1:4, $\mathrm{w} / \mathrm{v})$. Then, the homogenate was centrifuged at $900 \times \mathrm{g}$ at $4{ }^{\circ} \mathrm{C}$ for $5 \mathrm{~min}$. The supernatant was centrifuged at $12.500 \times g$ for $15 \mathrm{~min}$. The mitochondrial pellet was then washed once with an isolation medium and centrifuged under the same conditions. Finally, the mitochondrial pellet (MP) was reconstituted in a buffer solution $\left(\mathrm{Na}_{2} \mathrm{PO}_{4} /\right.$ $\mathrm{KH}_{2} \mathrm{PO}_{4}$ isotonized with $\mathrm{KCl}, \mathrm{pH}$ 7.4) and stored in aliquots.

\section{Plasma corticosterone level}

Corticosterone levels were estimated by the fluorescence method previously described by Zenker and Bernstein (1958). Briefly, aliquots of plasma were incubated with chloroform and centrifuged for $5 \mathrm{~min}$ at $900 \times \mathrm{g}$, followed by the addition of $0.1 \mathrm{M} \mathrm{NaOH}$ and another round of centrifugation. After the addition of the fluorescence reagent 
$\left(\mathrm{H}_{2} \mathrm{SO}_{4}\right.$ and ethanol 50\%), samples were centrifuged (5 min at $900 \times g$ ) and incubated at room temperature for $2 \mathrm{~h}$. After that, the fluorescence intensity emission was recorded at $540 \mathrm{~nm}$ (with $257 \mathrm{~nm}$ excitation) and corticosterone levels were expressed as ng corticosterone/ml plasma.

\section{MAO activity assay}

MAO activity was determined according to Krajl (1965), with some modifications. An aliquot of MP of each sample was incubated at $37{ }^{\circ} \mathrm{C}$ for $5 \mathrm{~min}$ in a medium containing buffer solution and specific inhibitors, selegiline (a MAO-B inhibitor, $250 \mathrm{nM}$ ) or clorgiline (a MAO-A inhibitor, $250 \mathrm{nM}$ ). Then, kynuramine dihydrobromide was added to the reaction mixture $(90 \mu \mathrm{M}(\mathrm{MAO}-\mathrm{A})$ and $60 \mu \mathrm{M}$ (MAOB)) as substrate. Samples were then incubated at $37^{\circ} \mathrm{C}$ for $30 \mathrm{~min}$. After incubation, the reaction was terminated by adding 10\% trichloroacetic acid (TCA). After cooling and centrifugation at $3000 \times \mathrm{g}$ for $15 \mathrm{~min}$, an aliquot of the supernatant was added to $1 \mathrm{M} \mathrm{NaOH}$. The fluorescence intensity was detected spectrofluorimetrically with excitation at $315 \mathrm{~nm}$ and emission at $380 \mathrm{~nm}$ (Shimadzu RF-5301 PC). Clorgiline $(100 \mathrm{nM})$ and selegiline $(100 \mathrm{nM})$ were used as positive controls in MAO-A and MAO-B assays, respectively. The concentration of 4-hydroxyquinoline (4-OH quinoline) was estimated from a corresponding standard fluorescence curve of 4-OH quinoline. MAO activity was expressed as nmol 4-OH quinoline/mg protein/min.

\section{Oxidative parameters}

Samples of the prefrontal cortex and hippocampus were collected to determine RS and TBARS levels. These measurements were performed to evaluate the effect of 4-PSQ on the modulation of cerebral oxidative stress.

RS levels were determined by a spectrofluorimetric method, using a 2', 7' dichlorofluorescein diacetate (DCHFDA) assay (Loetchutinat et al. 2005). Briefly, an aliquot of S1 was incubated with $1 \mathrm{mM}$ DCHF-DA and $10 \mathrm{mM}$ Tris- $\mathrm{HCl} \mathrm{pH}$ 7.4. The oxidation of DCFH-DA to fluorescent dichlorofluorescein (DCF) is measured for the detection of intracellular RS. The DCF fluorescence intensity emission was recorded at $520 \mathrm{~nm}$ (with $480 \mathrm{~nm}$ excitation) (Shimadzu RF-5301 PC). RS levels were expressed as units of fluorescence.

TBARS content was used as a marker of lipid peroxidation (Ohkawa et al. 1979). An aliquot of S1 was added to the reaction mixture containing: thiobarbituric acid $(0.8 \%)$, sodium dodecyl sulfate (8.1\%), and acetic acid (pH 3.4) and incubated at $95{ }^{\circ} \mathrm{C}$ for $2 \mathrm{~h}$. The absorbance was measured at $532 \mathrm{~nm}$ in a spectrophotometer (Shimadzu RF-5301 PC). Results were reported as nmol malondialdehyde (MDA)/mg protein.

\section{Antioxidant enzymes}

SOD activity was assayed spectrophotometrically as described by Misra and Fridovich (1972). This method is based on the capacity of SOD to inhibit the autoxidation of epinephrine. Briefly, $\mathrm{S} 1$ was diluted 1:10 (v/v) to determine SOD activity. An $\mathrm{S} 1$ aliquot was added to a $0.05 \mathrm{M} \mathrm{Na}_{2} \mathrm{CO}_{3}$ buffer and the enzymatic reaction was started by adding the epinephrine. The color reaction was measured at $480 \mathrm{~nm}$ (Shimadzu RF-5301 PC spectrophotometer). One unit of enzyme was defined as the amount of enzyme required to inhibit the rate of epinephrine autoxidation by $50 \%$ at $37{ }^{\circ} \mathrm{C}$. Results were expressed as units U SOD/mg protein.

GPx activity was evaluated spectrophotometrically (Shimadzu RF-5301 PC) using the method described by Wendel (1981) which involves monitoring the dismutation of $\mathrm{H}_{2} \mathrm{O}_{2}$ in the presence of $\mathrm{S} 1$ at $340 \mathrm{~nm}$. S1 was added to a system composed of reduced glutathione (GSH)/ nicotinamide adenine dinucleotide phosphate (NADPH)/ GR, and the enzymatic reaction was initiated by the addition of $\mathrm{H}_{2} \mathrm{O}_{2}$. In this assay, the enzyme activity is indirectly measured by NADPH decay. $\mathrm{H}_{2} \mathrm{O}_{2}$ is reduced and generates oxidized glutathione (GSSG) from GSH. GSSG is regenerated back to GSH by the GR present in the analysis medium at the expense of NADPH. Enzymatic activity was expressed as $\mathrm{nmol} \mathrm{NADPH} / \mathrm{min} / \mathrm{mg}$ protein.

GR activity was determined spectrophotometrically by a method described by Carlberg and Mannervik (1985). In this assay, GSSG is reduced by GR at the expense of NADPH consumption, which follows at $340 \mathrm{~nm}$ (Shimadzu RF-5301 $\mathrm{PC}$ spectrophotometer). An aliquot of S1 was added to the system containing $0.15 \mathrm{M}$ potassium phosphate buffer, $\mathrm{pH}$ 7.0, $1.5 \mathrm{mM}$ ethylene diamine tetra-acetic acid, $0.15 \mathrm{mM}$ NADPH. After the basal reading, the substrate $(20 \mathrm{mM}$ GSSG) was added to assess the activity in GR. Enzymatic activity was expressed as nmol NADPH/min/mg protein.

\section{RNA extraction and expression of NF-kB, PI3K, and AKT2 by real-time PCR}

Total mRNA was extracted from 50 to $100 \mathrm{mg}$ of prefrontal cortex and hippocampus tissue using TRIzol reagent (Invitrogen ${ }^{\mathrm{TM}}$, Carlsbad, USA) followed by DNase treatment with DNase I Amplification Grade (Invitrogen ${ }^{\mathrm{TM}}$, Carlsbad, USA) in order to ensure minimum DNA contamination of the samples. The total RNA isolated was quantified and its purity (260/280 and $260 / 230$ ratios) was examined by a NanoVuel spectrophotometer (GE, Fairfield, CT, USA).

The cDNA synthesis was performed using a HighCapacity cDNA Reverse Transcription kit (Applied Biosystems ${ }^{\mathrm{TM}}$, UK), according to the manufacturer's protocol. For reverse transcription, $1 \mu \mathrm{g}$ of total RNA was used in a reaction volume of $20 \mu \mathrm{l}$. The amplification was performed 
with GoTaq ${ }^{\circledR}$ qPCR Master Mix (Promega, Madison, WI) using the LightCycler ${ }^{\circledR} 96$ Real-Time PCR System (Roche Molecular Systems Inc., CA, USA) and the sequences of primers used are indicated in Table 1. The qPCR conditions were as follows: $10 \mathrm{~min}$ at $95^{\circ} \mathrm{C}$ to activate the hot-start Taq polymerase, followed by 35 cycles of denaturation for $15 \mathrm{~s}$ at $95{ }^{\circ} \mathrm{C}$, primer annealing for $60 \mathrm{~s}$ at $60^{\circ} \mathrm{C}$, and extension for $30 \mathrm{~s}$ at $72{ }^{\circ} \mathrm{C}$ (fluorescence signals were detected at the end of every cycle). Baseline and threshold values were automatically set by the LightCycler ${ }^{\circledR} 96$ Software. The number of PCR cycles required to reach the fluorescence threshold in each sample was defined as the $\mathrm{Ct}$ value. The $2^{-\Delta \Delta \mathrm{CT}}$ method was used to normalize the fold change in gene expressions (Livak and Schmittgen 2001), using GAPDH as the housekeeping gene.

\section{AChE activity}

The AChE enzymatic assay was performed according to the method of Ellman et al. (1961), with some modifications, using acetylthiocholine (AcSCh) as substrate. Briefly, an aliquot of $\mathrm{S} 1$ is added to a medium containing $100 \mathrm{mM}$ potassium phosphate buffer, $\mathrm{pH}$ 7.5. The enzymatic reaction is initiated by the addition of $0.5 \mathrm{mM} 5,5$-dithio-bis(2-nitrobenzoic acid) (DTNB), and $0.8 \mathrm{mM} \mathrm{AcSCh}$. The hydrolysis rate of the acetylcholin iodide was measured at $412 \mathrm{~nm}$ for $2 \mathrm{~min}$. Results were expressed as $\mu \mathrm{mol} \mathrm{AcSCh} / \mathrm{h} /$ $\mathrm{mg}$ protein.

\section{Protein determination}

The protein concentration was measured by the method of Bradford (1976), using bovine serum albumin as the standard.

\section{Statistical analysis}

Data are expressed as means \pm standard error of the mean (SEM). Data were analyzed by Graphpad Prism ${ }^{\circledR} 5$. D'Agostino and Pearson omnibus normality tests evaluated data normality. Statistical analysis was performed using a one-way analysis of variance (ANOVA) followed by Tukey's test, when appropriate. Values less than $0.05(p<0.05)$ were considered statistically significant.

\section{Results}

\section{4-PSQ attenuated ARS-induced depressive-like behavior without altering locomotor and exploratory activity}

The data analysis of OFT showed no change in the number of crossings (ANOVA: $F_{(5,36)}=0.9358, p=0.4696$ ) and rearings (ANOVA: $F_{(5,36)}=2.864, p=0.0281$ ) after the different treatments in mice (Fig. 2a and b).

The effects of treatments on the grooming time of mice in the SPT are presented in Fig. 2c. The data analysis of SPT demonstrated that mice exposed to ARS decreased (around $59 \%$ ) the grooming time when compared to the non-stressed control group. Treatment with 4-PSQ attenuated the grooming time of stressed mice. This effect was similar to the donepezil treatment but less than the administration of paroxetine in attenuating the grooming time in SPT. No changes in the grooming time in SPT were observed after per se treatment with 4-PSQ. (ANOVA: $F_{(5,36)}=35.71, p<0.0001$ ).

Figure $2 \mathrm{~d}$ shows the effect of the treatments on the immobilization time in the TST. The one-way ANOVA followed by Tukey's post hoc test revealed that mice submitted to ARS showed an increase (around 34\%) in the duration of immobility
Table 1 Primers used for quantitative real-time polymerase chain reaction. Listed are the forward and reverse primer sequences used to amplify each target gene as well as the GAPDH endogenous control

\begin{tabular}{|c|c|c|}
\hline Primer name & Sequence & Reference \\
\hline $\mathrm{NF}-\kappa \mathrm{B}$ forward & 5' AGAGAAGCACAGATACCACTAAG 3' & Li et al. (2017) \\
\hline $\mathrm{NF}-\kappa \mathrm{B}$ reverse & 5' CAGCCTCATAGAAGCCATCC 3' & \\
\hline IL-1 $\beta$ forward & 5' AGTTGACGGACCCCAAAAG 3' & Silverman et al. (2015) \\
\hline IL- $1 \beta$ reverse & 5' AGCTG GATGCTCTCATCAGG 3' & \\
\hline IL- 18 forward & 5' CAACTCAGGAGTCTTGCTCAACA 3' & Elhija et al. (2008) \\
\hline IL-18 reverse & 5' CAGGCCTGACATCTTCTGCAA 3' & \\
\hline IL-33 forward & 5' CTGCAAGTCAATCAGGCGAC 3' & Kurow et al. (2017) \\
\hline IL-33 reverse & 5' TGCAGCCAGATGTCTGTGTC 3' & \\
\hline PI3K forward & 5' CTCTCCTGTGCTGGCTACTGT 3' & Liu et al. (2014) \\
\hline $\mathrm{PI} 3 \mathrm{~K}$ reverse & 5' GCTCTCGGTTGATTCCAAACT 3' & \\
\hline AKT2 forward & 5' CAGCTGGGAGACCCAAGA 3' & Brand et al. (2015) \\
\hline AKT2 reverse & 5' CACACGCTGTCACCTAGCTT 3' & \\
\hline GAPDH forward & 5' TGCGACTTCAACAGCAACTC 3' & Bruckert et al. (2016) \\
\hline GAPDH reverse & 5' ATGTAGGCAATGAGGTCCAC 3' & \\
\hline
\end{tabular}



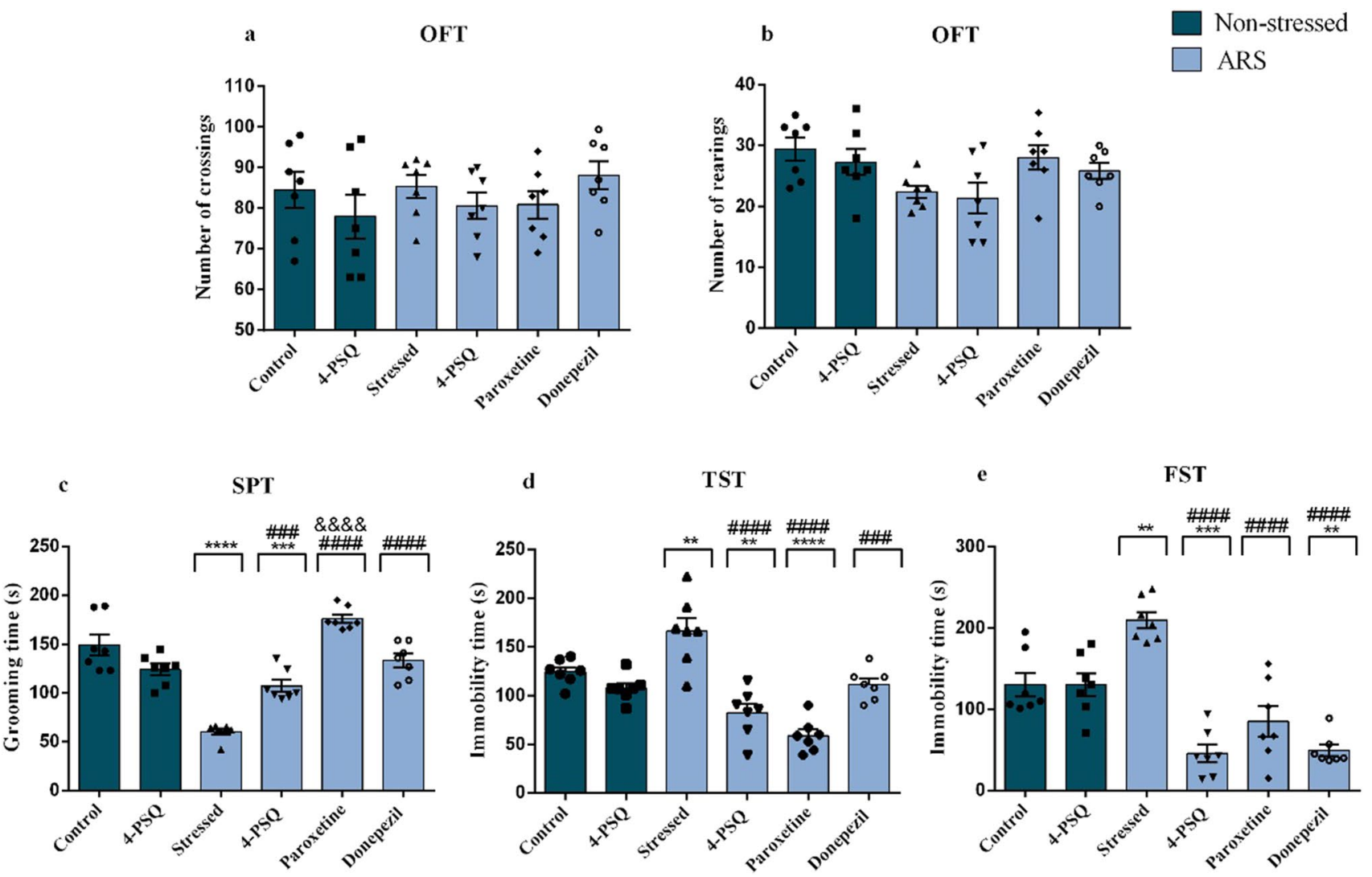

Fig. 2 Effect of 7-chloro-4-(phenylselanyl) quinoline (4-PSQ) or paroxetine or donepezil on the behaviors induced by acute restraint stress (ARS). a Crossings and $\mathbf{b}$ rearings in the open field test (OFT), c splash test (SPT), $\mathbf{d}$ tail suspension test (TST), and e forced swimming test (FST). Values are expressed as mean \pm standard error of the mean (S.E.M.) $(n=7)$. $(* *)$ denotes $p<0.01,(* * *)$ denotes $p<0.001$,

time, when compared to the non-stressed control group. The immobility time was attenuated by the 4-PSQ similarly to the treatment with the positive controls (paroxetine and donepezil). 4-PSQ per se did not change the immobility time in TSTin mice (ANOVA: $F_{(5,36)}=20.55, p<0.0001$ ).

Figure 2e shows the effect of 4-PSQ, paroxetine, and donepezil on the immobilization time in the FST. The post hoc analysis demonstrated that mice exposed to ARS showed an increase (around 61\%) in the duration of immobility time, when compared to the non-stressed control group. Treatment with 4-PSQ was able to attenuate the increase in immobility time induced by ARS similar to paroxetine and donepezil. Treatment with 4-PSQ per se did not change the behavior of mice in FST (ANOVA: $F_{(5,36)}=22.10, p<0.0001$ ).

\section{4-PSQ attenuated the memory impairment caused by ARS-induction}

The one-way ANOVA followed by Tukey's post hoc test revealed that ARS reduced (around 30\%) the spontaneous and $(* * * *)$ denotes $p<0.0001$ when compared to the non-stressed control group. (\#\#\#) denotes $p<0.001$ and (\#\#\#) denotes $p<0.0001$ when compared to the ARS-induced group. (\&\&\&\&) denotes $p<0.0001$ when compared to the ARS + 4-PSQ group (one-way ANOVA followed by Tukey's test)

alternation behavior in the Y-maze task, when compared to the non-stressed control group (Fig. 3a). This behavior was attenuated by treatment with 4-PSQ in a manner similar to donepezil. On the other hand, treatment with paroxetine did not alter the spontaneous alternation behavior in the Y-maze task. Treatment with 4-PSQ per se did not change the spontaneous alternation behavior of mice (ANOVA: $\left.F_{(5,36)}=6.447, p=0.0002\right)$. No change was observed in the number of arm entries after treatments in mice (ANOVA: $F_{(5,36)}=2.191, p=0.0767$ ) (data not shown).

Figures $3 \mathrm{~b}$ and $\mathrm{c}$ illustrate the results obtained in the STM and LTM in the ORT, respectively. One-way ANOVA followed by Tukey's test revealed that there was no difference in exploratory preference for objects between groups in the training phase (ANOVA: $F_{(5,36)}=2.836, p=0.0293$ ) (data not shown). On the other hand, ARS reduced (around $34 \%$ ) the exploratory preference for the new object in the STM, when compared to the non-stressed control group (Fig. 3b). This behavior was attenuated by treatment with 4-PSQ similar to donepezil, but it was superior to paroxetine 
Fig. 3 Effect of 7-chloro4-(phenylselanyl) quinoline (4-PSQ) or paroxetine or donepezil on the behaviors induced by acute restraint stress (ARS). a Y-maze task, b short-term memory (STM), and $\mathbf{c}$ long-term memory (LTM) in an object recognition test (ORT). Values are expressed as mean \pm standard error of the mean (S.E.M.) $(n=7) .(* *)$ denotes $p<0.01,(* * *)$ denotes $p<0.001$, and $(* * * *)$ denotes $p<0.0001$ when compared to the non-stressed control group. (\#) denotes $p<0.05$, (\#\#) $p<0.01$, (\#\#\#) denotes $p<0.001$, and (\#\#\#\#) denotes $p<0.0001$ when compared to the ARS-induced group. $(\& \&)$ denotes $p<0.01$ and $(\& \& \& \&)$ denotes $p<0.0001$ when compared to the ARS +4-PSQ group (one-way ANOVA followed by Tukey's test)
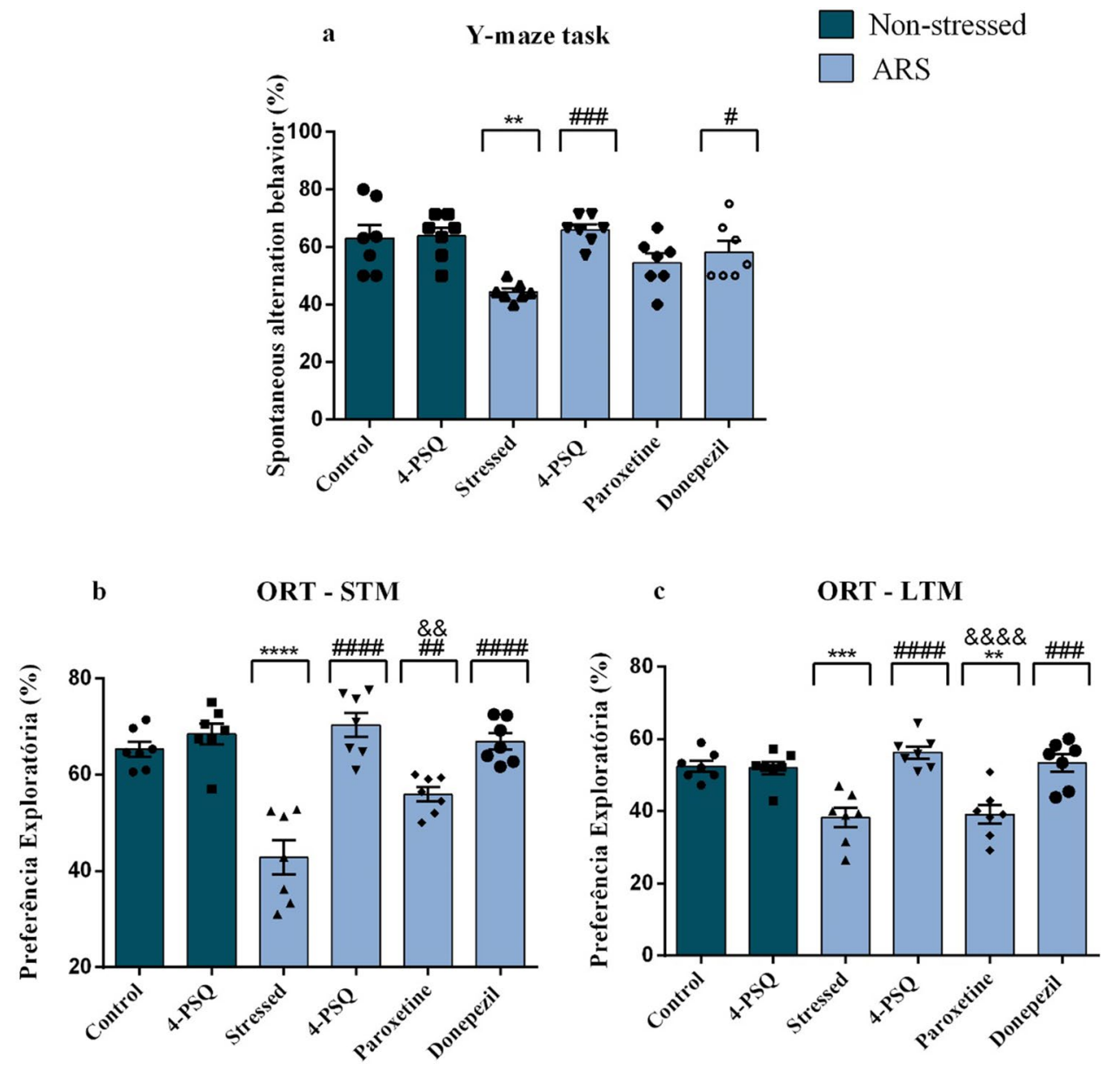

(ANOVA: $F_{(5,36)}=21.02, p<0.0001$ ). The results described in Fig. 3c demonstrate that ARS reduced (around 27\%) the exploratory preference for the new object in the LTM, when compared to the non-stressed control group (Fig. 3c), assessed $24 \mathrm{~h}$ after the training phase. Treatment with 4-PSQ attenuated this behavior similarly to donepezil. On the other hand, treatment with paroxetine did not alter the exploratory preference for the new object in LTM (ANOVA: $\left.F_{(5,36)}=13.21, p<0.0001\right)$. Treatment with 4-PSQ per se did not change the exploratory preference for the new object in STM and LTM on ORT.

\section{4-PSQ attenuated the HPA axis activation caused by ARS-induction}

As illustrated in Fig. 4, ARS increased (around 256\%) circulating corticosterone levels in stressed animals, when compared to the non-stressed control group. The effect of 4-PSQ in reducing corticosterone levels in stressed mice was similar to paroxetine, but it was superior to donepezil. 4-PSQ per se did not change the circulating corticosterone levels in mice (ANOVA: $F_{(5,36)}=40.40, p<0.0001$ ).

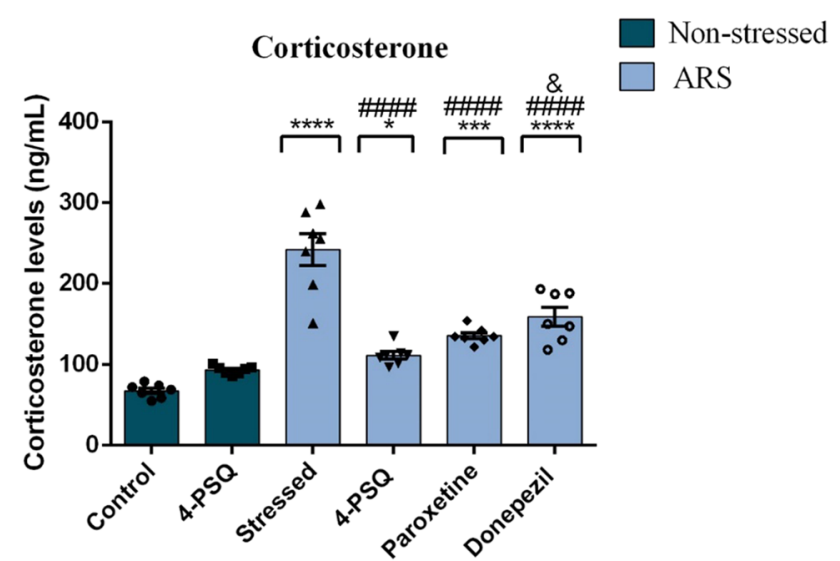

Fig. 4 Effect of 7-chloro-4-(phenylselanyl) quinoline (4-PSQ) or paroxetine or donepezil on corticosterone plasma levels in mice submitted to acute restraint stress (ARS). Values are expressed as mean \pm standard error of the mean (S.E.M.) $(n=7)$. (*) denotes $p<0.05$, (***) denotes $p<0.001$, and $(* * * *)$ denotes $p<0.0001$ when compared to the non-stressed control group. (\#\#\#) denotes $p<0.0001$ when compared to the ARS-induced group. (\&) denotes $p<0.05$ when compared to the ARS +4-PSQ group (one-way ANOVA followed by Tukey's test) 


\section{4-PSQ modulated the MAO-A and MAO-B enzymes activity in the prefrontal cortex and hippocampus of stressed mice}

The results described in Table 2 demonstrate that ARS increased MAO-A activity in the prefrontal cortex (around $216 \%$ ) and in the hippocampus (around 129\%) of mice, when compared to the non-stressed control group. MAO-A activity was normalized in the prefrontal cortex and hippocampus of stressed mice after treatment with 4-PSQ (Table 2). Paroxetine treatment normalized the activity of this enzyme only in the prefrontal cortex of stressed mice. On the other hand, donepezil was not able to normalize MAO-A activity in the evaluated brain structures. No changes in the activity of the MAO-A enzyme in the prefrontal cortex and hippocampus were observed after per se treatment with 4-PSQ (ANOVA: $F_{(5,36)}=22.77, p<0.0001$ for the prefrontal cortex; ANOVA: $F_{(5,36)}=9.47, p<0.0001$ for the hippocampus).

ARS increased MAO-B activity in the prefrontal cortex (around 88\%) and hippocampus (around 62\%), when compared to the non-stressed control group (Table 2). Treatment with 4-PSQ normalized MAO-B activity in the prefrontal cortex and hippocampus of stressed mice (Table 2). No changes were observed in MAO-B activity in cerebral structures of stressed mice after treatment with paroxetine or donepezil. 4-PSQ per se did not change MAO-B activity in the brain structures of mice (ANOVA: $F_{(5,36)}=6.15$, $p=0.0003$ for the prefrontal cortex; ANOVA: $F_{(5,36)}=4.70$, $p=0.0021$ for the hippocampus).

\section{4-PSQ reduced oxidative damage in the prefrontal cortex and hippocampus of stressed mice}

Figures 5a and $\mathrm{b}$ illustrate RS levels in the prefrontal cortex and hippocampus of mice. ARS increased RS levels in the prefrontal cortex (around 36\%) (Fig. 5a) and in the hippocampus (around 124\%) (Fig. 5b) of mice, when compared to the non-stressed control group. Treatment with 4-PSQ significantly reduced the production of RS caused by ARS in the cerebral structures (Fig. 5a and b). Treatment with donepezil reduced the formation of RS only in the hippocampus of stressed mice (Fig. 5b). However, the effect of 4-PSQ in reducing the RS levels in the hippocampus of stressed mice was superior to treatment with donepezil (Fig. 5b). The treatment with paroxetine noticeably reduced RS levels in the prefrontal cortex (Fig. 5a) and hippocampus (Fig. 5b) of stressed mice. No changes in the RS levels in the prefrontal cortex and hippocampus were observed after per se treatment with 4-PSQ (ANOVA: $F_{(5,36)}=8.15, p<0.0001$ for prefrontal cortex; ANOVA: $F_{(5,36)}=73.94, p=0.0001$ for hippocampus).

In the TBARS levels, ARS increased this parameter in the prefrontal cortex (around 32\%) (Fig. 5c) and in the hippocampus (around 38\%) (Fig. 5d), when compared to the non-stressed control group. 4-PSQ treatment reduced TBARS levels in the prefrontal cortex (Fig. 5c) and hippocampus (Fig. 5d) of stressed mice, while treatments with positive controls did not have any effect (Fig. $5 c$ on the prefrontal cortex and Fig. 5d hippocampus). 4-PSQ per se did not change the TBARS levels in the prefrontal cortex and hippocampus of mice (ANOVA: $F_{(5,36)}=4.563, p=0.0025$ for prefrontal cortex; ANOVA: $F_{(5,36)}=5.998, p=0.0004$ for hippocampus).

\section{4-PSQ modulated the antioxidant enzymes in the prefrontal cortex and hippocampus of stressed mice}

Figures $6 \mathrm{a}$ and $\mathrm{b}$ summarize the results of SOD activity in the prefrontal cortex and hippocampus, respectively, of mice after the experimental protocol. ARS increased the SOD activity in the prefrontal cortex (around 96\%) (Fig. 6a) and in the hippocampus (around 82\%) (Fig. 6b), when compared to the non-stressed control group. Treatment with 4-PSQ normalized the SOD activity in the cerebral structures of stressed mice, while donepezil and paroxetine did not have
Table 2 Effect of 7-chloro4-(phenylselanyl) quinoline (4-PSQ) or paroxetine or donepezil on the activity of monoamine oxidase (MAO)-A and $\mathrm{B}$ isoforms in the prefrontal cortex and hippocampus of mice subjected to acute restraint stress (ARS)

\begin{tabular}{llllll}
\hline & \multicolumn{2}{l}{ Prefrontal cortex } & & \multicolumn{2}{l}{ Hippocampus } \\
\cline { 2 - 3 } \cline { 5 - 6 } Experimental groups & MAO A & MAO B & & MAO A & MAO B \\
\hline Non-stressed - control & $0.54 \pm 0.09$ & $0.65 \pm 0.06$ & & $0.99 \pm 0.09$ & $1.05 \pm 0.09$ \\
Non-stressed - 4-PSQ & $0.82 \pm 0.05$ & $0.55 \pm 0.11$ & & $1.65 \pm 0.30$ & $1.60 \pm 0.06$ \\
ARS-stressed & $1.73 \pm 0.12^{* * * *}$ & $1.22 \pm 0.09^{* *}$ & & $2.26 \pm 0.14^{* *}$ & $1.71 \pm 0.11^{* *}$ \\
ARS - 4-PSQ & $0.42 \pm 0.04^{\# \# \# \#}$ & $0.68 \pm 0.08^{\#}$ & & $1.05 \pm 0.12^{\# \#}$ & $1.11 \pm 0.16^{\#}$ \\
ARS-Paroxetine & $1.46 \pm 0.15^{* * * * \&}$ & $0.93 \pm 0.14$ & & $1.28 \pm 0.20^{\#}$ & $1.28 \pm 0.12$ \\
ARS-Donepezil & $1.45 \pm 0.15^{* * * * \&}$ & $1.16 \pm 0.15^{*}$ & & $2.70 \pm 0.30^{* * * * *}$ & $1.58 \pm 0.17$
\end{tabular}

Values are expressed as mean \pm standard error of the mean (S.E.M.) $(n=7)$. (**) denotes $p<0.01$ and $(* * * *)$ denotes $p<0.0001$ when compared to the non-stressed control group. (\#) denotes $p<0.05$, (\#\#) denotes $p<0.01$, and (\#\#\#\#) denotes $p<0.0001$ when compared to the ARS-induced group. (\&) denotes $\mathrm{p}<0.05$ when compared to the ARS + 4-PSQ group (one-way ANOVA followed by Tukey's test) 
Fig. 5 Effect of 7-chloro4-(phenylselanyl) quinoline (4-PSQ) or paroxetine or donepezil on markers of oxidative stress in mice submitted to acute restraint stress (ARS). Reactive species (RS) levels in a prefrontal cortex and $\mathbf{b}$ hippocampus; thiobarbituric acid reactive species (TBARS) levels in $\mathbf{c}$ prefrontal cortex and $\mathbf{d}$ hippocampus. Values are expressed as mean \pm standard error of the mean (S.E.M.) $(n=7) .(*)$ denotes $p<0.05,(* *)$ denotes $p<0.01$, and $(* * * *)$ denotes $p<0.0001$ when compared to the non-stressed control group. (\#) denotes $p<0.05$ and (\#\#\#) denotes $p<0.0001$ when compared to the ARSinduced group. (\&\&) denotes $p<0.01$ and $(\& \& \& \&)$ denotes $p<0.0001$ when compared to the ARS + 4-PSQ group (one-way ANOVA followed by Tukey's test)
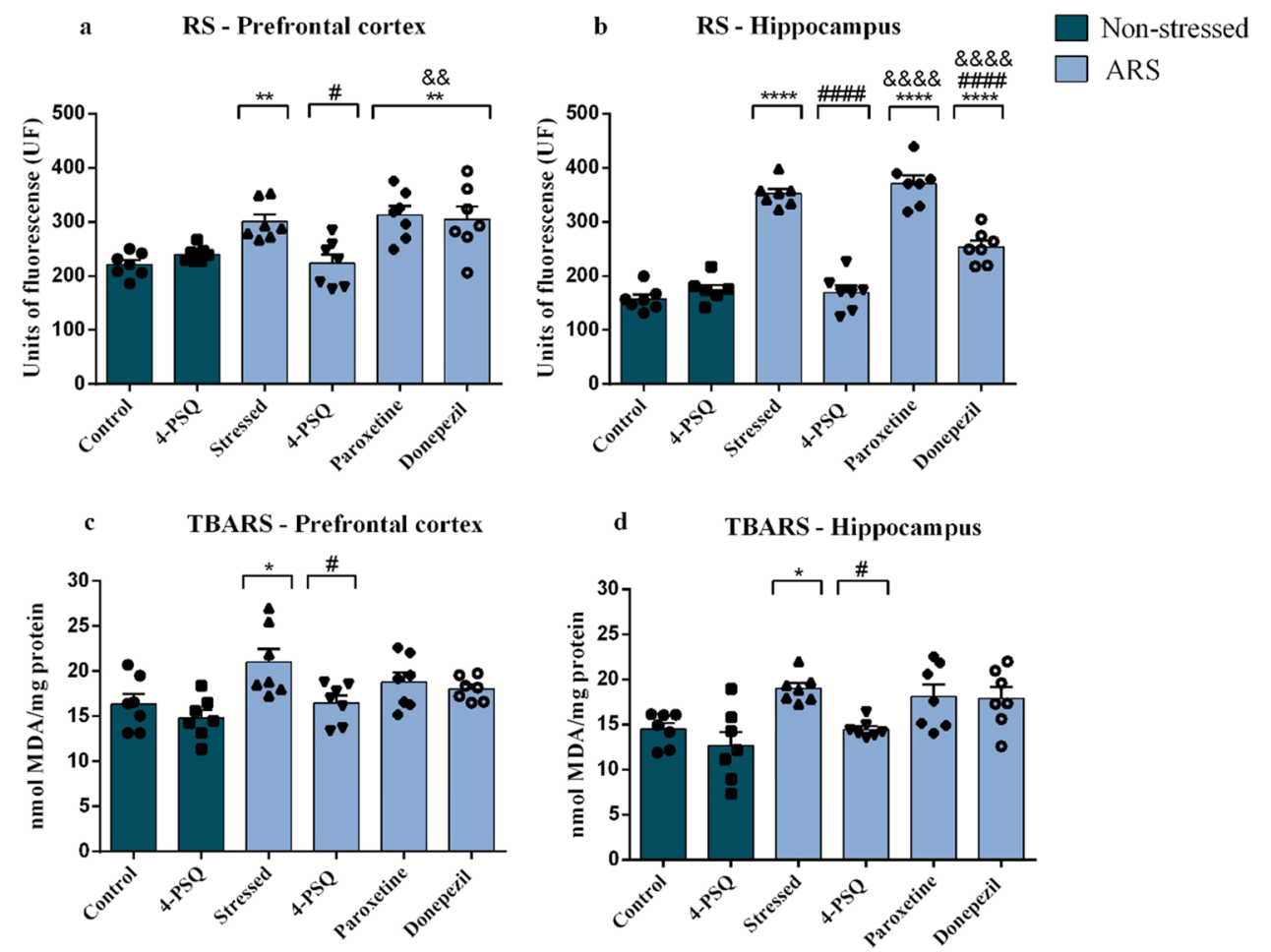

any effect (Fig. 6a for prefrontal cortex and Fig. 6b for hippocampus). No changes were observed in the SOD activity in the prefrontal cortex and hippocampus after per se treatment with 4-PSQ (ANOVA: $F_{(5,36)}=13.42, p<0.0001$ for the prefrontal cortex; ANOVA: $F_{(5,36)}=43.71, p<0.001$ for the hippocampus).

For GPx activity, the one-way ANOVA followed by Tukey's post hoc test showed that ARS increased enzyme activity in the prefrontal cortex (around 64\%) (Fig. 6c) and in the hippocampus (around 48\%) (Fig. 6d) of mice, when compared to the non-stressed control group. Treatment with 4-PSQ normalized the GPx activity in cerebral structures of stressed mice, and this effect was similar to paroxetine. On the other hand, the effect of donepezil was superior to that of 4-PSQ in normalizing the enzyme activity in the prefrontal cortex. 4-PSQ per se did not change the GPx activity in the prefrontal cortex and hippocampus of mice (ANOVA: $F_{(5,36)}=11.70, p<0.0001$ for the prefrontal cortex; ANOVA: $F_{(5,36)}=5.223, p=0.0010$ for the hippocampus).

GR activity in the prefrontal cortex and hippocampus of mice is shown in Fig. 6e and f, respectively. ARS increased GR activity in the prefrontal cortex (around 34\%) (Fig. 6e) and in the hippocampus (around 57\%) (Fig. 6f) of mice, when compared to the non-stressed control group. Treatment with 4-PSQ normalized GR activity in the prefrontal cortex (Fig. 6e) and hippocampus (Fig. 6f) of stressed mice, while treatment with paroxetine normalized enzyme activity only in the hippocampus of stressed mice (Fig. 6f). Donepezil had no effect in normalizing GR activity in the brain structures of stressed mice (Fig. 6e for the prefrontal cortex and Fig. $6 f$ for the hippocampus). No changes in GR activity were observed after per se treatment with 4-PSQ in the evaluated brain structures (ANOVA: $F_{(5,36)}=6.326$, $p=0.0003$ for the prefrontal cortex; ANOVA: $F_{(5,36)}=6.292$, $p=0.0001$ for the hippocampus).

\section{4-PSQ modulated the NF-KB, IL-1 $\beta$, IL-18, IL-33, $P I 3 K$, and AKT2 levels in the prefrontal cortex and hippocampus of stressed mice}

Figure 7 illustrates the effects of treatment with 4-PSQ on NF- $\kappa B$, IL-1 $\beta$, IL-18, IL- 33, PI3K, and AKT2 mRNA expression levels in the prefrontal cortex and hippocampus of mice exposed to the ARS protocol. ARS increased the mRNA expression levels of NF- $\mathrm{kB}$ in the prefrontal cortex (around 34\%) (Fig. 7a) and hippocampus (around 37\%) (Fig. 7b), when compared to the non-stressed control. Treatment with 4-PSQ normalized this increase in the prefrontal cortex and hippocampus of stressed mice, similarly to paroxetine and donepezil. 4-PSQ per se did not change the mRNA expression levels of NF- $\mathrm{KB}$ in the prefrontal cortex and hippocampus of mice (ANOVA: $F_{(5,24)}=9.894, p<0.0001$ for the prefrontal cortex; ANOVA: $F_{(5,24)}=15.45, p<0.0001$ for the hippocampus).

ARS increased IL- $1 \beta$ expression in the prefrontal cortex (around 70\%) (Fig. 7a), when compared to the nonstressed control group, but no changes were found in the hippocampus of stressed mice (Fig. 7b). Treatment with 
Fig. 6 Effect of 7-chloro4-(phenylselanyl) quinoline (4-PSQ) or paroxetine or donepezil on the activity of antioxidant enzymes in mice submitted to acute restraint stress (ARS). Superoxide dismutase (SOD) activity in a prefrontal cortex and $\mathbf{b}$ hippocampus; Glutathione peroxidase (GPx) activity in c prefrontal cortex and $\mathbf{d}$ hippocampus; Glutathione reductase (GR) activity in e prefrontal cortex and $\mathbf{f}$ hippocampus. Values are expressed as mean \pm standard error of the mean (S.E.M.) $(n=7)$. $(*)$ denotes $p<0.05$, $(* *)$ denotes $p<0.01,(* * *)$ denotes $p<0.001$, and $(* * * *)$ denotes $p<0.0001$ when compared to the non-stressed control group. (\#) denotes $p<0.05$, (\#\#) denotes $p<0.01$, (\#\#\#) denotes $p<0.001$, and (\#\#\#) denotes $p<0.0001$ when compared to the ARS-induced group. (\&) denotes $p<0.05$ and (\&\&) denotes $p<0.01$ when compared to the ARS +4-PSQ group (one-way ANOVA followed by Tukey's test)
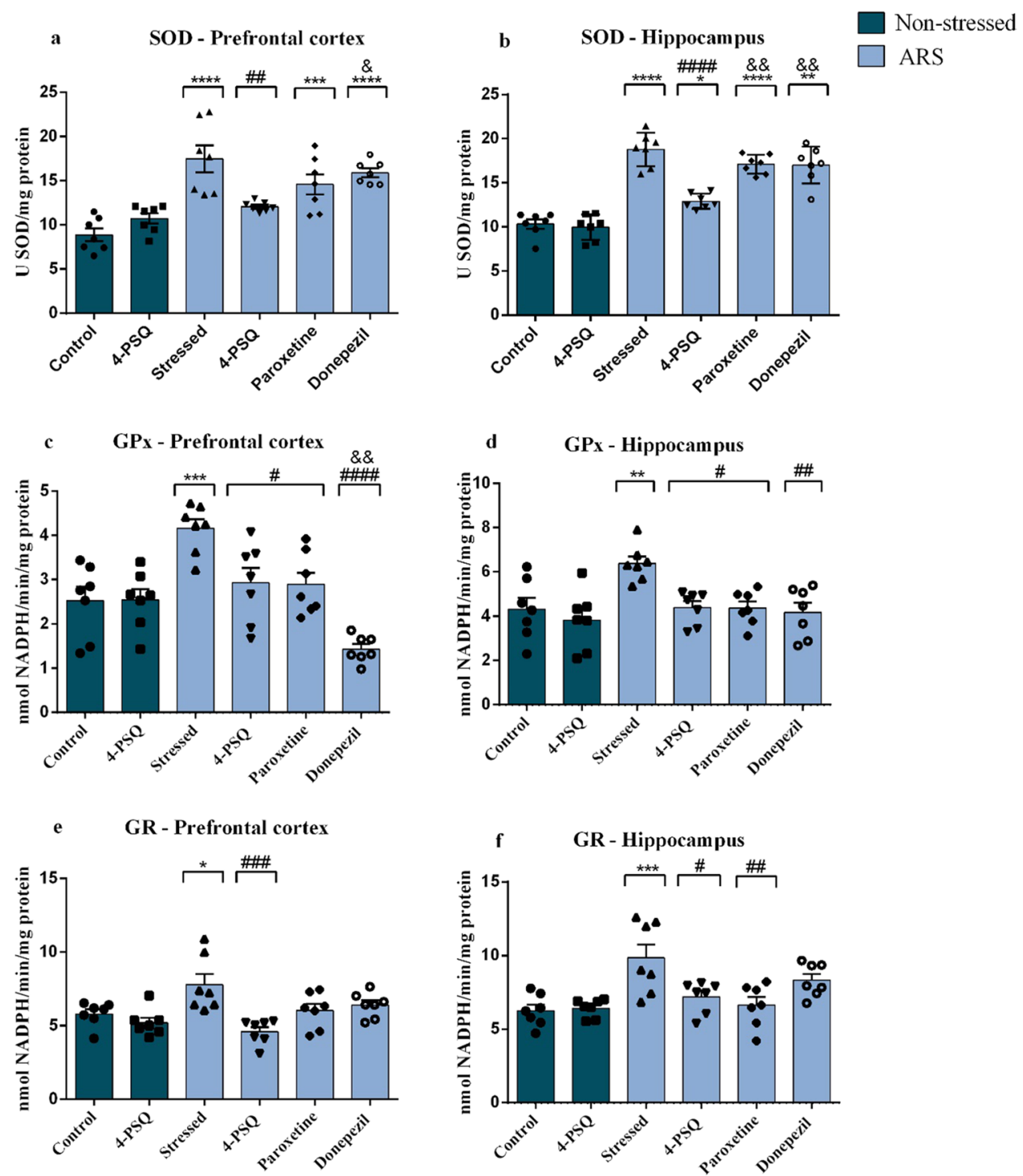

4-PSQ significantly normalized the mRNA expression levels of IL- $1 \beta$ in the prefrontal cortex of stressed mice, similar to paroxetine. On the other hand, the effect of 4-PSQ was superior to that of donepezil. No changes in the mRNA expression levels of IL- $1 \beta$ were observed after per se treatment with 4-PSQ in the evaluated brain structures (ANOVA: $F_{(5,24)}=19.82, p<0.0001$ for the prefrontal cortex; ANOVA: $F_{(5,24)}=19.16, p<0.0001$ for the hippocampus).

IL-18 expression in the prefrontal cortex and hippocampus of mice is shown in Fig. 7a and b, respectively. ARS increased IL-18 expression in the prefrontal cortex (around 182\%) (Fig. 7a), when compared to the non-stressed control group, but no changes were found in the hippocampus of stressed mice (Fig. 7b). Treatment with 4-PSQ normalized the mRNA expression levels of IL-18 in the prefrontal cortex of stressed mice, similarly to paroxetine and donepezil. No changes in the IL-18 expression were observed after per se treatment with 4-PSQ in the evaluated brain structures (ANOVA: $F_{(5,24)}=24.32, p<0.0001$ for the prefrontal cortex; ANOVA: $F_{(5,24)}=4.45, p=0.0052$ for the hippocampus).

In the IL-33 expression, ARS increased this parameter in the prefrontal cortex (around 185\%) (Fig. 7a), when compared to the non-stressed control group, but no changes were found in the hippocampus of stressed mice (Fig. 7b). 4-PSQ treatment normalized the mRNA expression levels of IL-33 in the prefrontal cortex of stressed mice, similarly to paroxetine and donepezil. 4-PSQ per se did not change the IL-33 expression in the prefrontal cortex and hippocampus of mice (ANOVA: $F_{(5,24)}=74.40, p<0.0001$ for prefrontal cortex; ANOVA: $F_{(5,24)}=1.245, p=0.3196$ for hippocampus).

ARS decreased PI3K expression in the prefrontal cortex (around 45\%) (Fig. 7a), when compared to the nonstressed control group, but no changes were found in the 

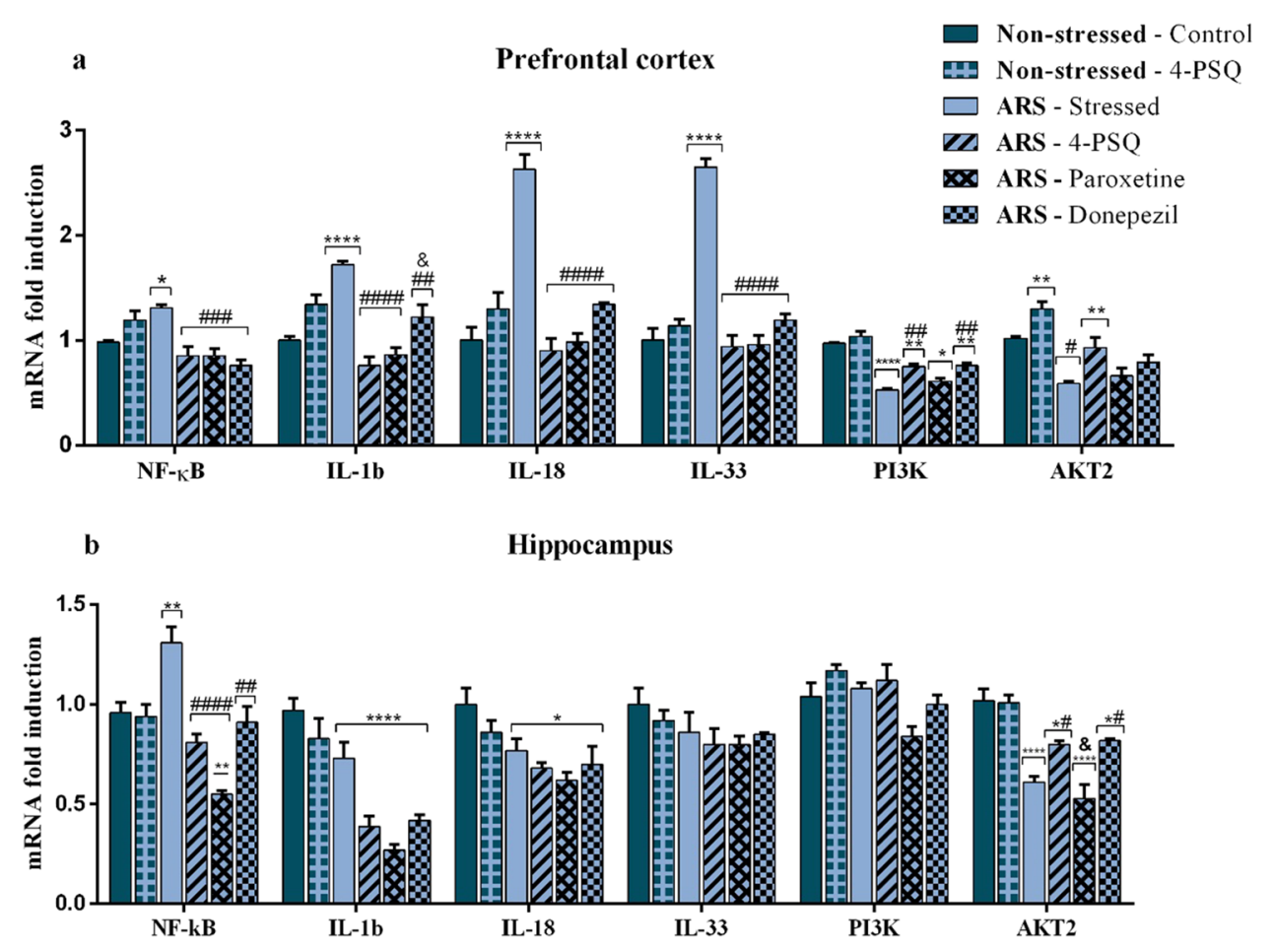

Fig. 7 Effect of 7-chloro-4- (phenylselanyl) quinoline (4-PSQ) or paroxetine or donepezil on the levels of mRNA expression of cell signaling molecules in mice subjected to acute restraint stress (ARS). Nuclear factor-kappa B (NF-kB) in a prefrontal cortex and b hippocampus; Interleukin (IL)- $1 \beta$ in a prefrontal cortex and $\mathbf{b}$ hippocampus; IL-18 in a prefrontal cortex and b hippocampus; IL-33 in a prefrontal cortex and $\mathbf{b}$ hippocampus; Phosphoinositide-3 kinase $(\mathrm{PI} 3 \mathrm{~K})$ in a prefrontal cortex and $\mathbf{b}$ hippocampus; Protein kinase

hippocampus of stressed mice (Fig. 7b). Treatment with 4-PSQ significantly normalized the mRNA expression levels of PI3K in the prefrontal cortex of stressed mice, similarly to donepezil while paroxetine had no changes on mRNA expression levels of PI3K in the brain structures evaluated. No changes in the mRNA expression levels of PI3K were observed after per se treatment with 4-PSQ in the evaluated brain structures (ANOVA: $F_{(5,24)}=30.99, p<0.0001$ for the prefrontal cortex; ANOVA: $F_{(5.24)}=4,220, p=0.0068$ for the hippocampus).

ARS decreased the mRNA expression levels of AKT2 in the prefrontal cortex (around 42\%) (Fig. 7a) and hippocampus (around 40\%) (Fig. 7b), when compared to the non-stressed control group. Treatment with 4-PSQ significantly reversed the decrease in mRNA expression levels of AKT2 in the prefrontal cortex and hippocampus of stressed mice, while donepezil had an effect only on the hippocampus (Fig. 7a for prefrontal cortex and Fig. 7b for hippocampus). No changes were observed in the mRNA expression levels of AKT2 in cerebral structures of stressed mice after treatment with paroxetine (Fig. 7a for the prefrontal cortex and Fig. $7 \mathrm{~b}$ for the hippocampus). 4-PSQ per se did not change
B -2 (AKT2) in a prefrontal cortex and b hippocampus. Values are expressed as mean \pm standard error of the mean (S.E.M.) $(n=5)$. $(*)$ denotes $p<0.05,(* *)$ denotes $p<0.01$ and $(* * * *)$ denotes $p<0.0001$ when compared to the non-stressed control group. (\#) denotes $p<0.05$, (\#\#) denotes $p<0.01$, (\#\#\#) denotes $p<0.001$, and (\#\#\#) denotes $p<0.0001$ when compared to the ARS-induced group. (\&) denotes $p<0.05$ when compared to the ARS + 4-PSQ group (one-way ANOVA followed by Tukey's test)

the mRNA expression levels of AKT2 in the brain structures of mice (ANOVA: $F_{(5,24)}=16.39, p<0.0001$ for the prefrontal cortex; ANOVA: $F_{(5,24)}=21.12, p<0.0001$ for the hippocampus).

\section{4-PSQ modulated the AChE activity in the prefrontal cortex and hippocampus of stressed mice}

Results showed that ARS increased the AChE activity in the prefrontal cortex (around 120\%) (Fig. 8a) and in the hippocampus (around 31\%) (Fig. 8b) of mice, when compared to the non-stressed control group. Enzyme activity was completely normalized in the prefrontal cortex (Fig. 8a) and hippocampus (Fig. 8b) of stressed mice after treatment with 4-PSQ. Treatment with paroxetine or donepezil partially normalized AChE activity in the prefrontal cortex (Fig. 8a), but they completely normalized it in the hippocampus (Fig. 8b) of stressed mice. No changes were observed in the activity of the AChE enzyme in the prefrontal cortex and hippocampus after per se treatment with 4-PSQ (ANOVA: $F_{(5,36)}=11.07$, $p<0.0001$ for the prefrontal cortex; ANOVA: $F_{(5,36)}=6.967$, $p<0.0001$ for the hippocampus). 


\section{Discussion}

The present study revealed, for the first time, the effect of the administration of 4-PSQ, a quinoline functionalized with the organoselenium group, in an ARS-induction protocol in mice. It was found that 4-PSQ attenuated depressive-like and self-care behaviors, as well as memory impairment induced by stress. Based on the evidence, we believe that the effects of 4-PSQ may be associated, at least in part, with the (I) attenuation of HPA axis activation; (II) attenuation of alterations in the monoaminergic system; (III) modulation of oxidative stress; (IV) modulation of the transcription factors involved in neuroinflammation and neuroplasticity; and (V) restoration of the cholinergic system (Fig. 9). These results suggest the pharmaceutical potential of 4-PSQ for the treatment of comorbidities, depression, and memory impairment.

In view of studies prospecting new drugs, the use of agents containing the quinoline nucleus for the treatment of diseases has been receiving attention in our research. In this context, several studies demonstrated that the quinoline fraction is the pharmacophore of several anti-AD drugs (Freeman and Dawson 1991; Mancino et al. 2009; Oz et al. 2009; Jiang et al. 2011). In parallel, selenium is an essential micronutrient for the body and plays a critical role in the proper functioning of several selenoproteins involved in the brain's antioxidant defenses (Sher 2000). Given its neuroprotective role in neuronal function, recent studies have investigated a relationship between selenium levels in preventing AD onset and progression and in depression (Wang et al. 2018; Varikasuvu et al. 2019). In addition, it is worth emphasizing that previous studies by our research group have shown that the phenylselanyl group present in the quinoline structure is critical for the antioxidant activity of 4-PSQ in a model of cerebral oxidative stress induced by sodium nitroprusside (Vogt et al. 2018). In this context, we have demonstrated the importance of selenium in positive biomedical effects of 4-PSQ.

Moreover, Couto et al. (2019) demonstrated that 4-PSQ was able to restore selenium levels in the head and body of Drosophila melanogaster flies in a Parkinson-like disease model, preventing the damage caused in this model. The authors suggested that 4-PSQ was able to penetrate the blood-brain barrier (BBB), since high levels of selenium in the heads of flies were observed after treatment with 4-PSQ (Couto et al. 2019). In addition, Barth et al. (2021) demonstrated that treatment with 4-PSQ restored plasma selenium levels in elderly rats, thus contributing to the restoration of damage caused by aging. Therefore, it is suggested that 4-PSQ is able to reach the bloodstream after its absorption (Barth et al. 2021). In this sense, considering that complex disorders, such as depression and memory impairment, are more likely to be attenuated through the simultaneous modulation of multiple targets, the versatility of 4-PSQ led us to consider its use as a possible therapeutic strategy for comorbidities depression and memory impairment.

Recent studies have shown that stress has a negative impact on the mental health of the population ( $\mathrm{Li}$ et al. 2020; Huang and Zhao 2020). Among the main issues linked to stress is the current world situation, with the COVID-19 pandemic. Important data reveal that when the pandemic began, social isolation was proposed as one of the most effective measures to combat the spread of the new coronavirus SARS-CoV-2 (severe acute respiratory syndrome coronavirus 2) (Adalja et al. 2020). Despite this, social isolation has had a negative psychological influence, through increased psychosocial stress, anxiety, and neuropsychiatric symptoms, revealing significant psychiatric morbidities (Holmes et al. 2020; Xiang et al. 2020). Thus, society
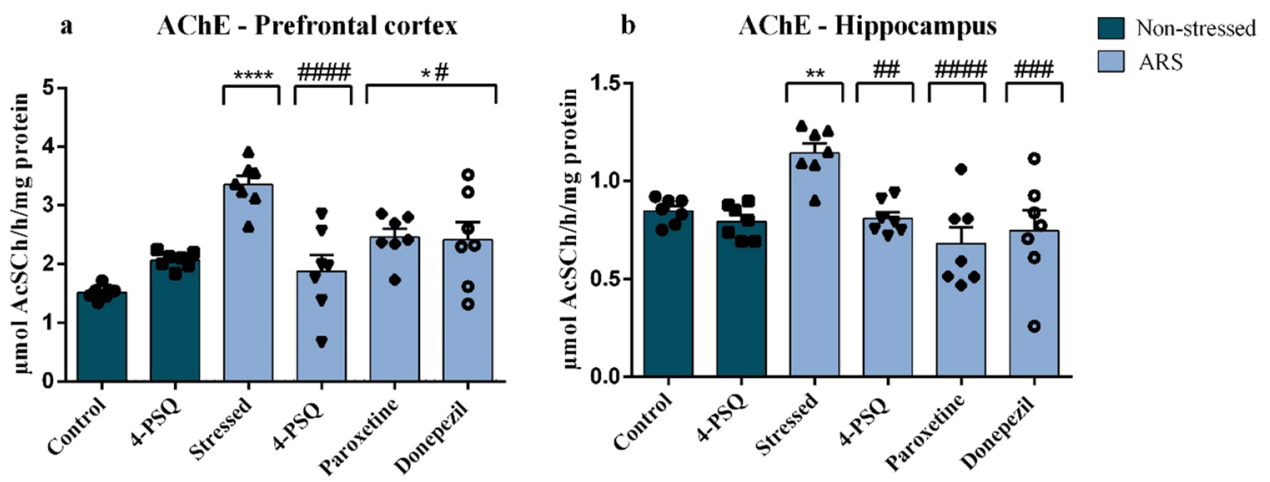

Fig. 8 Effects of 7-chloro-4-(phenylselanyl) quinoline (4-PSQ) or paroxetine or donepezil on the activity of acetylcholinesterase (AChE) in a prefrontal cortex and $\mathbf{b}$ hippocampus in mice submitted to acute restraint stress (ARS). Values are expressed as mean \pm standard error of the mean (S.E.M.) $(n=7)$. $(*)$ denotes $p<0.05,(* *)$ denotes $p<0.01$, and $(* * * *)$ denotes $p<0.0001$ when compared to the non-stressed control group. (\#) denotes $p<0.05$, (\#\#) denotes $p<0.01$, (\#\#\#) denotes $p<0.001$, and (\#\#\#) denotes $p<0.0001$ when compared to the ARS-induced group (one-way ANOVA followed by Tukey's test) 


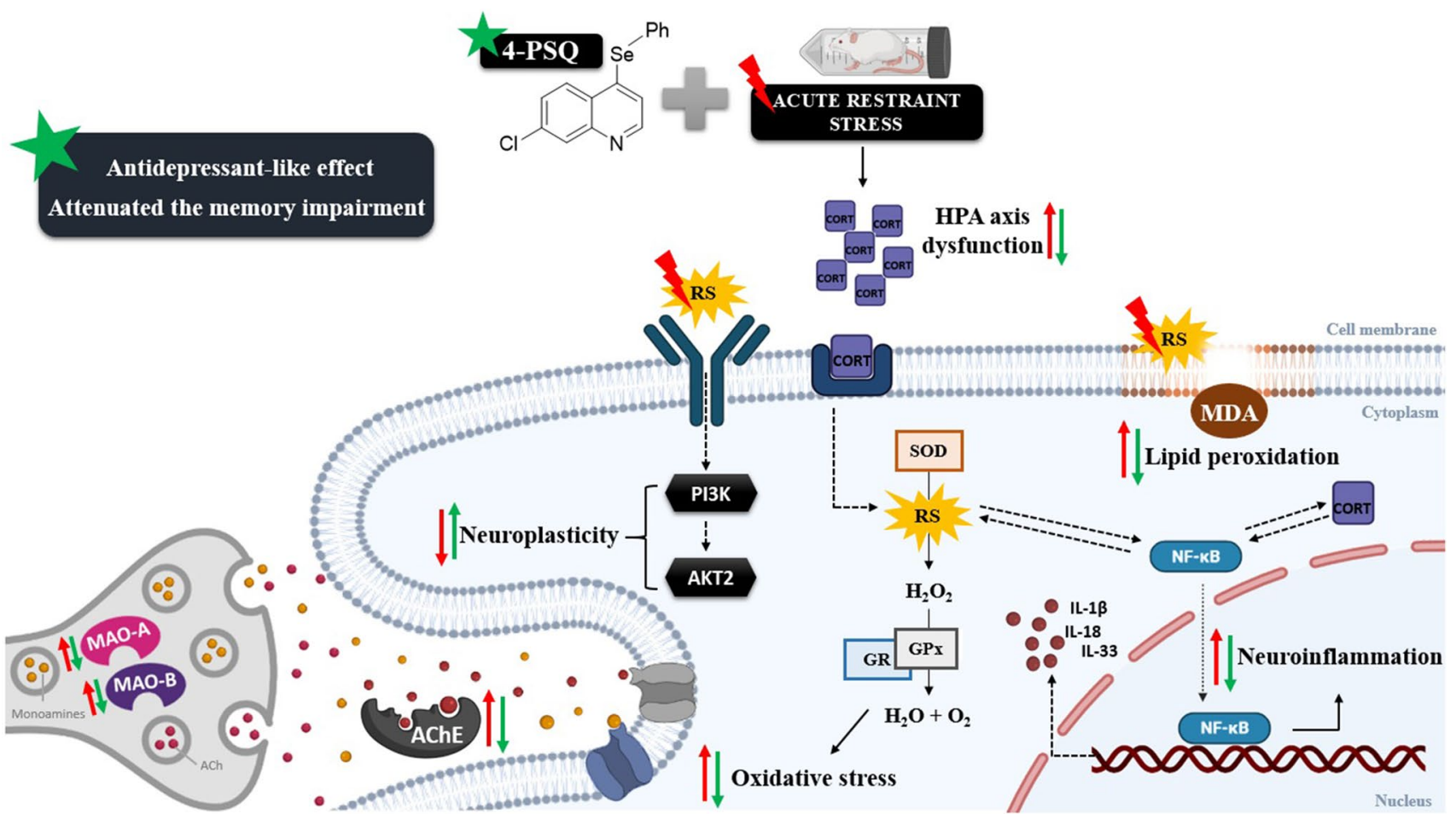

Fig. 9 Summary of the effects of acute containment stress (ARS) on the monoaminergic system, oxidative pathways, neuroplasticity, neuroinflammatory pathway, hypothalamic-pituitary-adrenal (HPA) axis, cholinergic system, and the possible targets of 7-chloro-4(phenylselanyl) quinoline (4-PSQ). Treatment with 4-PSQ HPA attenuates the activation of the HPA axis by reducing plasma corticosterone (CORT) levels, attenuates changes in the monoaminergic system, by reestablishing the activity of isoforms of the monoaminooxidase (MAO) (MAO-A and MAO-B) enzyme, modulating oxidative stress, reducing levels of reactive species (RS), thiobarbituric acid reactive species (TBARS) and activity of antioxidant enzymes (superoxide dismutase [SOD], glutathione peroxidase [GPx] and glutathione

urgently needs to achieve an understanding of psychosocial stress. According to this, understanding of mechanisms involved in the depression and memory impairment dyad, caused by stress is extremely important in order to study new therapeutic alternatives capable of reducing psychosocial stress and associated symptoms.

In view of this, ARS was proposed as an accepted stressinducing experimental model to investigate depressive-like behavior, as well as its relationship with memory impairment in rodents (Baker and Kim 2002; Walesiuk et al. 2005; Li et al. 2012; Mosaffa et al. 2021; Niksiyar et al. 2021). In response to stress, the HPA axis is rapidly activated and results in the release of glucocorticoids (Del Giudice et al. 2011). ARS is a validated model for causing hyperactivation of the HPA axis, with a notable increase in plasma corticosterone levels (Joseph and Golden 2017). The action of these glucocorticoids occurs mainly through their binding to their receptors in the brain, the glucocorticoid receptor, and the reductase $[\mathrm{GR}]$ ), attenuates neuroinflammation by reducing the lev-

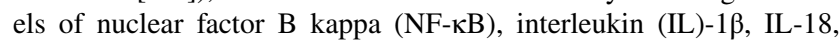
and IL-33, positively modulated the transcription factors (phosphatidylinositol-3-kinase [PI3K] and protein kinase B-2 [AKT2]) involved in neuroplasticity and finally modulated the cholinergic system by reducing the activity of the acetylcholinesterase ( $\mathrm{AChE}$ ) enzyme. Based on the evidence, we believe that this set of results contributed to the reduction of depressive-like behavior and the memory impairment induced by ARS. Abbreviations: ACh, acetylcholine; MDA, malondialdehyde; $\mathrm{H}_{2} \mathrm{O}_{2}$, hydrogen peroxide; $\mathrm{H}_{2} \mathrm{O}$, molecule of water; $\mathrm{O}_{2}$, molecular oxygen

mineralocorticoid receptor in order to lead complementarily to the regular activity of the HPA axis (Harris et al. 2013). Mineralocorticoid receptors are involved in basal conditions and at the beginning of activation of the HPA axis during stress and are therefore important for the development of stress resilience (Joels and de Kloet 2017). On the other hand, glucocorticoid receptors are activated after stress is established, thus leading to a reduction in the activity of the HPA axis (de Kloet et al. 2018). Accordingly, an imbalance between mineralocorticoid receptors and glucocorticoid receptor signaling may contribute to a dysregulation of the HPA axis in response to stress, thus contributing mainly to the development of mood disorder; however, little is known about the underlying molecular mechanisms between this relationship (Harris et al. 2013; Joels and de Kloet 2017; de Kloet et al. 2018).

In the present study, ARS-induced activation of the HPA axis was confirmed by the increase in plasma corticosterone 
levels in stressed mice. Importantly, our results demonstrated that 4-PSQ treatment was able to attenuate the activation of the HPA axis by reducing the plasma corticosterone levels, with an effect similar and superior to positive controls used in this study (paroxetine and donepezil, respectively). It is known that deregulation of the HPA axis causes the binding of cortisol to its glucocorticoid receptors and mineralocorticoid receptors in the limbic system, mainly in the hippocampus and prefrontal cortex that have a high density of these receptors (Lowy et al. 1984). Consequently, neuronal atrophy occurs in these regions, resulting in emotional changes and memory dysfunction, symptoms that are found in patients with depression and AD (Lupien et al. 2009; Colciago et al. 2015). In this context, we confirmed that ARS caused depressive-like behavior, as demonstrated by increasing immobility time in TST and FST, and memory impairment, as demonstrated by reducing spontaneous alternations in the Y-maze task and reducing exploratory preference for the new object in the ORT. In accordance, other authors showed that the ARS protocol increased the immobility time in TST and FST (Mosaffa et al. 2021; Niksiyar et al. 2021). In addition, a study by Wolf (2008) reported that elevated cortisol responses in humans in the presence of psychosocial stressors triggered impairments in tasks that required participants to remember information previously learned. Another study found that sustained elevation of corticosterone had deleterious effects on the structure and function of important brain regions in animal models (Mcewen and Gianaros 2010). In this way, our data confirmed that the hyperactivation of the HPA axis contributed to the development of depressive-like behavior and memory impairment observed in animals submitted to ARS.

Moreover, patients with depression have reduced self-care behavior, a symptom that can be assessed in the SPT through grooming time (Freitas et al. 2014). However, the physiological mechanisms of a relationship between stress and self-care behavior are not fully understood. It is believed that a possible mechanism to explain this relationship is the neural reward circuits, since the self-cleansing behavior induces endocrine and neural responses even under stress-free conditions (Dunlop and Nemeroff 2007; Shiota et al. 2016). Accordingly, a study by Van Erp et al. (1994) demonstrated that self-cleaning time is correlated with plasma levels of the adrenocorticotropic hormone (responsible for stimulating the release of cortisol), suggesting that this behavior is linked to the neuroendocrine response to stress. In view of this, our results showed that ARS reduced self-care behavior, demonstrating that stress can induce depression with characteristics very similar to those found in humans, as already indicated previously (Vasconcelos et al. 2015; Gong et al. 2016).

It is important to highlight that in this study, 4-PSQ treatment attenuated depressive-like behavior (as demonstrated by reducing immobility time in TST and FST), work memory (as evidenced by increasing spontaneous alternation behavior in the Y-maze test), STM, and LTM (as demonstrated by the increase in exploratory preference for the new object in the ORT), and a symptom of self-care behavior (as shown by increasing grooming time in SPT). In this context, our results highlight that 4-PSQ has an antidepressant-like action and has a role in improving memory, supporting its pharmacological effect in the treatment of stress-induced comorbidities (depression and memory impairment). We can suggest that, at least in part, 4-PSQ mitigated behavioral changes by its ability to normalize corticosterone levels, attenuating the activation of the HPA axis. Importantly, our results demonstrated that the 4-PSQ treatment was able to attenuate the behavior changes similarly to positive controls used in this study (paroxetine and donepezil). Moreover, none of the treatments caused changes in the spontaneous locomotor and exploratory activities of mice, indicating, mainly, that the effect of 4-PSQ is not due to nonspecific changes, such as psychostimulant activity. Hence, this is an important result since psychostimulant drugs may give a false-positive result in animal models (Cryan et al. 2005).

As already mentioned, stress has a major impact on different biological systems in the brain, including the monoaminergic system (Higuchi et al. 2017), an important target that has been studied in depression and memory impairment/DA comorbidity, with reduced levels of monoamines in the CNS (Vermeiren et al. 2014; Otte et al. 2016; Behl et al. 2021). MAO is the enzyme of the monoaminergic system responsible for regulating the levels of monoaminergic neurotransmitters, such as serotonin (5-HT), norepinephrine, and/or dopamine, through their oxidative deamination, thus reducing the availability of these monoamines in synapses (Finberg and Rabey 2016). This enzyme exists in two enzymatic isoforms, MAO-A and MAO-B, which differ in their substrate and inhibitor specificity and in their tissue distribution (Shih et al. 1999). Selective MAO-A isoform inhibitors act as potent antidepressants, while MAO-B inhibitors are useful in neurodegenerative disorders such as in $\mathrm{AD}$ (Saura et al. 1994). Thus, the dual inhibition of MAO-A and MAO-B may be valuable for the therapy of depression and memory impairment/DA comorbidity. According to this, the evaluation of MAO isoforms became a target in this study. Our results show that ARS induced an increase in the activity of MAO-A and MAO-B isoforms in the prefrontal cortex and hippocampus of mice. Thus, an increase in MAO isoform activity is associated with an imbalance in the monoaminergic system, with a reduction in neurotransmitters; and based on the evidence, we believe that this has contributed to the depressive-like behavior and memory impairment observed in our study. On the other hand, treatment with 4-PSQ attenuated the changes in MAO-A and MAO-B activity in the prefrontal cortex and hippocampus of stressed 
mice, being useful for the treatment of the comorbidity in question. According to this, studies demonstrate that modulation of the monoaminergic system with increased levels of monoamines at synapses reverses some of the impacts caused by stress (Holsboer 2000; Jiang et al. 2019).

There is evidence that stress can make the brain vulnerable to oxidative damage, through the activation of intracellular pathways involved in the formation of free radicals, and consequently, it produces behavioral changes related to neuropsychiatric disorders (Che et al. 2015). In this sense, studies report a relationship between HPA axis hyperactivation and an increase in oxidative parameters (Balmus et al. 2016; Kv et al. 2018). At the cellular level, glucocorticoids, such as corticosterone, favor the increase in the metabolic rate in conjunction with catecholamines, and in turn in this process, there is an increase in RS production (Balmus et al. 2016). In the present study, our results demonstrated that ARS increased RS production and favored lipid peroxidation, as evidenced by increasing TBARS levels in the prefrontal cortex and hippocampus of mice. Furthermore, we observed an increase in SOD, GPx, and GR activities in the cerebral structures of mice submitted to ARS. Indeed, an increase in RS levels induced by stress favors the process of lipid peroxidation and changes in antioxidant defenses in limbic regions (Kim et al. 2016), causing an impairment of the antioxidant state in the brain (Moretti et al. 2013; Sousa et al. 2018; Casaril et al. 2019). Moreover, SOD, GPx, and GR are the main antioxidant defenses responsible for maintaining the redox balance (Kulak et al. 2013) and an increase in these enzyme activities is an attempt to eliminate the RS generated by ARS in cerebral structures. In accordance, some reports showed results similar to those found in our study, in which ARS caused an increase in RS content, lipid peroxidation, and SOD, GPX, and GR activities in the prefrontal cortex and hippocampus of rodents (Moretti et al. 2013; Sousa et al. 2018; Casaril et al. 2019). Therefore, based on the evidence we believe that the neurotoxic effects of hyperactivation of the HPA axis induced by stress may have helped the oxidative stress process, contributing to the development of depressive-like behavior and memory impairment.

In the present study, oxidative changes induced by ARS were reversed by treatment with 4-PSQ, as evidenced by normalization of the RS content, lipid peroxidation, and activity of antioxidant enzymes, with an action similar or superior to positive controls (donepezil and paroxetine). These results demonstrate that 4-PSQ treatment is able to reverse neuronal oxidative damage and modulate the antioxidant defense system. Previously, 4-PSQ showed that it modulated oxidative stress in different experimental models (Pinz et al. 2016, 2018; Luchese et al. 2020; Paltian et al. 2020; Lemos et al. 2021; Rodrigues et al. 2021). These results are supported by a study by Vogt et al. (2018) in which he demonstrated the antioxidant action of 4-PSQ in a cerebral oxidative stress model in mice, and they evidenced that compound action is entirely attributed to the presence of the organoselenium group in the molecule. Indeed, we cannot say whether 4-PSQ acts directly in the redox state or whether it modulates other pathways/systems, reducing the process of cerebral oxidative stress. However, we can assume that 4-PSQ acts on different lines of antioxidant defense, by attenuating neuronal oxidative damage and reestablishing the antioxidant defense system, as evidenced by its beneficial effect against depressive-like behavior and impairment of memory caused by ARS.

In addition, hyperactivation of the HPA axis in response to stress progressively generates an inflammatory environment (de Baumont et al. 2019). In the current study, we found that ARS increased NF- $\mathrm{kB}$ mRNA expression levels in the prefrontal cortex and hippocampus of stressed animals. ARS also increased the expression levels of IL-1 $\beta$, IL-18, and IL-33 mRNA in the prefrontal cortex of mice. In fact, neuroinflammatory events are orchestrated by transcription factors, such as NF- $\kappa \mathrm{B}$, which can be activated by different stimuli, such as stress, the presence of RS, and inflammatory responses (Siomek 2012; Balmus et al. 2016). $\mathrm{NF}-\kappa \mathrm{B}$ plays a key role in inflammation through its ability to modulate the transcription of numerous pro-inflammatory genes, such as IL-1 $\beta$, IL-18, and IL-33 (Jope et al. 2017). This deregulation of pro-inflammatory cytokines ultimately favors oxidative imbalance and consequently causes an increase in RS production, which can synergistically induce tissue damage, neuroinflammation, neurodegeneration, and neuronal apoptosis (Bakunina et al. 2015). In parallel, another key component in these responses is the action of pro-inflammatory cytokines on the hypothalamus, promoting an exacerbated increase in the release of cortisol, and consequently triggering hyperactivity of the HPA axis (Iwata et al. 2013). In view of these mechanisms, previous reports have shown that NF- $\kappa B$ activation as well as the increase in pro-inflammatory cytokines is strongly related to the development of depressive-like behavior and memory impairment in rodents (O'Neill and Kaltschmidt 1997; Miller et al. 2009; Eyre and Baune 2012; Heppner et al. 2015). According to Koo et al. (2010) stress-induced anhedonia, one of the main symptoms of depression, depends on NF- $\mathrm{KB}$ activation. In parallel, previous studies describe that IL- $1 \beta$ and NF- $\kappa B$ signaling is activated by stressful events, indicating that this signaling pathway is necessary for the antineurogenic and behavioral effects of stress (Miller et al. 2009; Koo et al. 2010). Additionally, the overexpression of IL-18 and IL-33 is linked to neuroinflammatory processes, resulting in neuropsychiatric and cognitive changes (Alboni et al. 2010; Kudinova et al. 2016).

According to the above, our results are consistent with previous studies, as ARS induced the expression of NF- $\mathrm{KB}$ 
and pro-inflammatory cytokines such as IL-1 $\beta$, IL-18, and IL-33 in mouse brain structures. In this context, based on the evidence, we believe that HPA axis hyperactivation and increased oxidative stress were essential for NF- $\mathrm{KB}$ nuclear translocation, promoting the transcription of proinflammatory genes and thus initiating a neuroinflammatory response. In contrast, it is suggested that these neuroinflammatory responses contributed to the development of depressive-like behavior and memory impairment in stressed mice. Nonetheless, an important finding of our study was that 4-PSQ treatment reversed the increase in neuroinflammatory parameters (NF-kB, IL-1 $\beta$, IL-18, and IL-33) in the prefrontal cortex and/or in the hippocampus of stressed mice, similar or superior to the positive controls (paroxetine and donepezil). We suggested that the effect of 4-PSQ in modulating neuroinflammation is associated with the attenuation of HPA axis activation and reduction of oxidative stress in the prefrontal cortex and hippocampus of stressed mice. Accordingly, previous studies have demonstrated that the attenuation of the HPA axis and oxidative stress is correlated with the reduction of neuroinflammatory processes (Casaril et al. 2019; Paltian et al. 2020). Thus, our findings demonstrated the importance of the therapeutic use of 4-PSQ, since it was able to attenuate neuroinflammation and oxidative stress, as well as the activation of the HPA axis, reducing depressive-like symptoms and memory impairment caused by stress.

Notably, in order to adapt to stressful events, intracellular signal transduction pathways are activated to promote neuronal survival and neuroplasticity (Begni et al. 2017). Outstanding among these signaling pathways is PI3K/AKT which is involved in synaptic plasticity, learning, memory, and depression (Yang et al. 2008; Qi et al. 2016), and can modulate neurotransmitter release, cell viability, apoptosis, and postsynaptic responses ( $\mathrm{Li}$ et al. 2015b). The PI3K enzyme is activated in the presence of growth factors, hormones, cytokines, and/or neurotransmitters. Its lipid products act as second messengers, since they activate proteins such as AKT, being the effector of PI3K for cellular responses (Beaulieu 2012). Taking into account the significant role of PI3K/AKT signaling pathway modulation in the mechanisms underlying depression and memory impairment and in an attempt to advance our understanding of the mechanisms involved in the effect of 4-PSQ, it was found useful to assess this pathway. PI3K activates the three AKT isoforms: AKT1, AKT2, and AKT3 (Beaulieu 2012; Li et al. 2015b). In this study, we chose to evaluate the AKT2 mRNA expression, due to its participation in the regulation of neuron differentiation and survival, in addition to its inhibition being associated with psychiatric diseases, such as depression (Deng et al. 2019). We found that the mRNA expression of PI3K and AKT was reduced in the prefrontal cortex in stressed mice. Regarding the hippocampal response, only AKT2 mRNA expression levels were reduced after ARS in mice. A study by Cunha et al. (2015) reported that the activation of these kinases can affect sub-regions of the brain, making their detection difficult. In this way, based on the evidence we believe that this may have influenced our results, considering that we did not detect changes in the levels of PI3K mRNA expression in the hippocampus. Thus, other detection techniques, such as immunoblotting or even assessing other sub-regions, will be targets for future studies to better elucidate this pathway. According to this, our results suggested an involvement of the PI3K/AKT2 signaling pathway in the effect of 4-PSQ, considering that the compound was able to normalize PI3K and AKT2 mRNA expression levels in the prefrontal cortex, contributing to the reestablishment of neuroplasticity processes and behavioral changes. These effects of treatment with 4-PSQ were similar to the effect of the positive controls (paroxetine and donepezil).

We also investigated the activity of $\mathrm{AChE}$ in an attempt to expand the action mechanisms of 4-PSQ. AChE is responsible for maintaining the proper functioning of the cholinergic system by maintaining the levels of the neurotransmitter acetylcholine (ACh) (English and Webster 2012). Our results showed that ARS induced an increase in AChE activity in the prefrontal cortex and hippocampus of mice. Thus, an increase in AChE activity is associated with an imbalance in the cholinergic, system with loss of brain function, and based on the evidence, we believe that this contributed to the memory impairment observed in our study. The reduction in ACh levels is mainly responsible for causing memory impairment, an important mechanism that leads to neurodegeneration (Lu et al. 2018). Interestingly, treatment with 4-PSQ attenuated the memory impairment induced by ARS and normalized the stimulation of AChE activity in the prefrontal cortex and hippocampus of mice, similarly to paroxetine and donepezil. Previous studies have also pointed out that 4-PSQ exhibited a neuroprotective effect and an important improvement in parameters associated with cognition in animal models by modulating the cholinergic system (Rodrigues et al. 2021; Barth et al. 2019; Pinz et al. 2018). Thus, we can suggest that one of the possible justifications for the neuroprotector effect of 4-PSQ on memory impairment is the modulation of AChE activity, associated with the ability to modulate oxidative stress and synaptic plasticity regulation of the PI3K/AKT pathway, mechanisms that are associated with memory disorders and neuropsychiatric diseases, such as depression.

The findings of this study are highly important, since the treatments available for depression are not effective against the associated memory impairment (Galts et al. 2019). Thus, the adverse effects of antidepressants are added to those of drugs used for the treatment of $\mathrm{AD}$ (which mitigate memory impairment), and as a consequence, there is a reduction in the quality of life of the patient affected by this comorbidity 
(Banerjee et al. 2013). Thus, one of the main advantages of 4-PSQ is the possibility of a single drug for the treatment of two diseases, depression and its comorbidity, memory impairment/AD.

\section{Conclusion}

In conclusion, 4-PSQ exhibited an antidepressant-like effect and attenuated the memory impairment induced by ARS in mice. Based on the evidence, we believe that these effects are associated, at least in part, with its ability to attenuate the activation of the HPA axis, attenuate changes in the monoaminergic system, modulate oxidative stress, restore neuroplasticity, modulate the cholinergic system, and attenuate neuroinflammation. Therefore, the findings of this study support the use of 4-PSQ as a possible promising alternative for the treatment of depression associated with stress-induced memory impairment. Thus, we are motivated to continue investigating the potential of this compound in search of new mechanisms linked to its effect.

Author contribution R.L.O. performed the experiments, the analysis of data, and wrote the manuscript. R.L.O., G.T.V., K.C.R., and M.P.P. performed the experiments. R.L.O., E.A.W., and C.L. designed the project. A.L. and D.A. synthesized the compound 4-PSQ E.B., W.B.D., and V.F.C. performed the genetic expression. E.A.W. and C.L. supervised the experiments. All authors critically reviewed the content and approved the final version for publication.

Funding We are grateful to Universidade Federal de Pelotas (UFPel), Conselho Nacional de Desenvolvimento Científico e Tecnológico (CNPq) (UNIVERSAL 429859/2018-0), Fundação de Amparo à Pesquisa do Estado do Rio Grande do Sul (FAPERGS) (PRONEM 16/2551-0000240-1, PqG 17/2551-0001013-2 and 19/2551-00017456 ) for financial support. This study was also financed in part by the Coordenação de Aperfeiçoamento de Pessoal de Nível superior - Brasil (CAPES)-Finance Code 001. R.L.O. is the recipient of a CAPES fellowship. V.F.C, D.A., E.A.W., and C.L. are recipients of CNPq fellowships.

\section{Declarations}

Conflict of interest The authors declare no competing interests.

\section{References}

Adalja AA, Toner E, Inglesby TV (2020) Priorities for the US Health Community Responding to COVID-19. JAMA 323:1343-1344. https://doi.org/10.1001/jama.2020.3413

Alboni S, Cervia D, Sugama S, Conti B (2010) Interleukin 18 in the CNS. J Neuroinflammation 7:9. https://doi.org/10.1186/ 1742-2094-7-9

Anisman H, Merali Z, Hayley S (2008) Neurotransmitter, peptide and cytokine processes in relation to depressive disorder: comorbidity between depression and neurodegenerative disorders. Prog Neurobiol 85:1-74

Baker KB, Kim JJ (2002) Effects of stress and hippocampal NMDA receptor antagonism on recognition memory in rats. https:// doi.org/10.1101/lm.46102

Bakunina N, Pariante CM, Zunszain PA (2015) Immune mechanisms linked to depression via oxidative stress and neuroprogression. Immunology 144:365-373. https://doi.org/10.1111/imm.12443

Balmus IM, Ciobica A, Antioch I, et al (2016) Oxidative stress implications in the affective disorders: main biomarkers, animal models relevance, genetic perspectives, and antioxidant approaches. https://doi.org/10.1155/2016/3975101

Banerjee S, Hellier J, Romeo R, et al (2013) Study of the use of antidepressants for depression in dementia: the Hta-saDD trial-a multicentre, randomised, double-blind, placebo-controlled trial of the clinical effectiveness and cost-effectiveness of sertraline and mirtazapine. Health Technol Assess (Rockv) 17. https:// doi.org/10.3310/hta17070

Barth A, Vogt A, Reis A et al (2019) 7-Chloro-4-(Phenylselanyl) Quinoline with memory enhancer action in aging rats: modulation of neuroplasticity, acetylcholinesterase activity, and cholesterol levels. Mol Neurobiol. https://doi.org/10.1007/ s12035-019-1530-5

Beaulieu J-M (2012) A role for Akt and glycogen synthase kinase-3 as integrators of dopamine and serotonin neurotransmission in mental health. J Psychiatry Neurosci 37:7-16. https://doi.org/ 10.1503/jpn.110011

Begni V, Riva MA, Cattaneo A (2017) Cellular and molecular mechanisms of the brain-derived neurotrophic factor in physiological and pathological conditions. Clin Sci 131:123-138. https:// doi.org/10.1042/CS20160009

Behl T, Kaur D, Sehgal A et al (2021) Role of monoamine oxidase activity in Alzheimer's disease: an insight into the therapeutic potential of inhibitors. Molecules 26:3724. https://doi.org/10. 3390/molecules26123724

Bradford MM (1976) A rapid and sensitive method for the quantitation of microgram quantities of protein utilizing the principle of protein-dye binding. Anal Biochem 72:248-254. https://doi. org/10.1016/0003-2697(76)90527-3

Brand Y, Levano S, Radojevic V, et al (2015) All Akt Isoforms (Akt1, Akt2, Akt3) Are involved in normal hearing, but only Akt 2 and Akt 3 are involved in auditory hair cell survival in the mammalian inner ear. https://doi.org/10.1371/journal.pone. 0121599

Bruckert G, Vivien D, Docagne F, Roussel BD (2016) Normalization of reverse transcription quantitative PCR data during ageing in distinct cerebral structures. Mol Neurobiol 53:1540-1550. https://doi.org/10.1007/s12035-015-9114-5

Caraci F, Copani A, Nicoletti F, Drago F (2010) Depression and Alzheimer's disease: neurobiological links and common pharmacological targets. Eur J Pharmacol 626:64-71

Carlberg I, Mannervik B (1985) Glutathione reductase. Methods Enzymol 113:484-490. https://doi.org/10.1016/S0076-6879(85) 13062-4

Casaril AM, Domingues M, Bampi SR et al (2019) The selenium-containing compound 3-((4-chlorophenyl)selanyl)-1-methyl-1H-indole reverses depressive-like behavior induced by acute restraint stress in mice: modulation of oxido-nitrosative stress and inflammatory pathway. Psychopharmacology 236:2867-2880. https:// doi.org/10.1007/s00213-018-5151-x

Che Y, Zhou Z, Shu Y et al (2015) Chronic unpredictable stress impairs endogenous antioxidant defense in rat brain. Neurosci Lett 584:208-213. https://doi.org/10.1016/j.neulet.2014.10.031

Chi S, Yu J-T, Tan M-S, Tan L (2014) Depression in Alzheimer's disease: epidemiology, mechanisms, and management. J Alzheimers Dis 42. https://doi.org/10.3233/JAD-140324 
Colciago A, Casati L, Negri-Cesi P, Celotti F (2015) Learning and memory: steroids and epigenetics. J Steroid Biochem Mol Biol 150. https://doi.org/10.1016/j.jsbmb.2015.02.008

Couto SF, Araujo SM, Bortolotto VC et al (2019) 7-chloro-4(phenylselanyl) quinoline prevents dopamine depletion in a Drosophila melanogaster model of Parkinson's-like disease. J Trace Elem Med Biol 54:232-243. https://doi.org/10.1016/j. jtemb.2018.10.015

Cryan JF, Page ME, Lucki I (2005) Differential behavioral effects of the antidepressants reboxetine, fluoxetine, and moclobemide in a modified forced swim test following chronic treatment. Psychopharmacology 182:335-344. https://doi.org/10.1007/ s00213-005-0093-5

Cunha M, Budni J, Ludka F, et al (2015) Involvement of PI3K/Akt signaling pathway and its downstream intracellular targets in the antidepressant-like effect of creatine. Mol Neurobiol 53. https://doi.org/10.1007/s12035-015-9192-4

de Baumont A, Bortoluzzi A, Wollenhaupt de Aguiar B et al (2019) Anxiety disorders in childhood are associated with youth IL-6 levels: a mediation study including metabolic stress and childhood traumatic events. J Psychiatr Res 115:43-50. https://doi. org/10.1016/j.jpsychires.2019.05.011

de Kloet ER, Meijer OC, de Nicola AF et al (2018) Importance of the brain corticosteroid receptor balance in metaplasticity, cognitive performance and neuro-inflammation. Front Neuroendocrinol 49:124-145. https://doi.org/10.1016/j.yfrne.2018.02.003

Del Giudice M, Ellis BJ, Shirtcliff EA (2011) The adaptive calibration model of stress responsivity. Neurosci Biobehav Rev 35:1562-1592. https://doi.org/10.1016/j.neubiorev.2010.11. 007

Deng Z, Yuan C, Yang J et al (2019) Behavioral defects induced by chronic social defeat stress are protected by Momordica charantia polysaccharides via attenuation of JNK3/PI3K/AKT neuroinflammatory pathway. Ann Transl Med 7:6. https://doi. org/10.21037/atm.2018.12.08

Domingues M, Casaril AM, Birmann PT et al (2019) Effects of a selanylimidazopyridine on the acute restraint stress-induced depressive- and anxiety-like behaviors and biological changes in mice. Behav Brain Res 366:96-107. https://doi.org/10. 1016/j.bbr.2019.03.021

Duarte LFB, Barbosa ES, Oliveira RL et al (2017) A simple method for the synthesis of 4-arylselanyl-7-chloroquinolines used as in vitro acetylcholinesterase inhibitors and in vivo memory improvement. Tetrahedron Lett 58:3319-3322. https://doi.org/ 10.1016/j.tetlet.2017.07.039

Dunlop BW, Nemeroff CB (2007) The role of dopamine in the pathophysiology of depression. Arch Gen Psychiatry 64:327-337. https://doi.org/10.1001/archpsyc.64.3.327

Elhija M, Lunenfeld E, Huleihel M (2008) LPS increases the expression levels of IL-18, ICE and IL-18 R in mouse testes. Am J Reprod Immunol 60:361-371. https://doi.org/10.1111/j.16000897.2008.00636.x

Ellman GL, Courtney KD, Andres V, Featherstone RM (1961) A new and rapid colorimetric determination of acetylcholinesterase activity. Biochem Pharmacol 7:88-95. https://doi.org/10.1016/ 0006-2952(61)90145-9

English BA, Webster AA (2012) Acetylcholinesterase and its inhibitors. In: Primer on the Autonomic Nervous System. Elsevier Inc 631-633

Eyre H, Baune B (2012) Neuroplastic changes in depression: a role for the immune system. Psychoneuroendocrinology 37:13971416. https://doi.org/10.1016/j.psyneuen.2012.03.019

Finberg JPM, Rabey JM (2016) Inhibitors of MAO-A and MAO-B in psychiatry and neurology. Front Pharmacol 7:340. https:// doi.org/10.3389/fphar.2016.00340
Freeman SE, Dawson RM (1991) Tacrine: a pharmacological review. Prog Neurobiol 36:257-277. https://doi.org/10.1016/03010082(91)90002-I

Freitas AE, Bettio LEB, Neis VB et al (2014) Agmatine abolishes restraint stress-induced depressive-like behavior and hippocampal antioxidant imbalance in mice. Prog Neuro-Psychopharmacology Biol Psychiatry 50:143-150. https://doi.org/10.1016/j. pnpbp.2013.12.012

Freitas AE, Machado DG, Budni J et al (2013) Fluoxetine modulates hippocampal cell signaling pathways implicated in neuroplasticity in olfactory bulbectomized mice. Behav Brain Res 237:176184. https://doi.org/10.1016/j.bbr.2012.09.035

Galts C, Bettio L, Jewett D, et al (2019) Depression in neurodegenerative diseases: common mechanisms and current treatment options. Neurosci Biobehav Rev 102. https://doi.org/10.1016/j. neubiorev.2019.04.002

Gong M-J, Han B, Wang S et al (2016) Icariin reverses corticosterone-induced depression-like behavior, decrease in hippocampal brain-derived neurotrophic factor (BDNF) and metabolic network disturbances revealed by NMR-based metabonomics in rats. J Pharm Biomed Anal 123:63-73. https://doi.org/10.1016/j.jpba. 2016.02.001

Harris AP, Holmes MC, de Kloet ER et al (2013) Mineralocorticoid and glucocorticoid receptor balance in control of HPA axis and behaviour. Psychoneuroendocrinology 38:648-658. https://doi. org/10.1016/j.psyneuen.2012.08.007

Heppner FL, Ransohoff RM, Becher B (2015) Immune attack: the role of inflammation in Alzheimer disease. Nat Rev Neurosci 16:358-372. https://doi.org/10.1038/nrn3880

Heun R, Schoepf D, Potluri R, Natalwala A (2013) Alzheimer's disease and co-morbidity: Increased prevalence and possible risk factors of excess mortality in a naturalistic 7-year follow-up. Eur Psychiatry 28:40-48. https://doi.org/10.1016/j.eurpsy.2011.06.001

Higuchi Y, Soga T, Parhar IS (2017) Regulatory pathways of monoamine oxidase a during social stress. Front Neurosci 11:604. https:// doi.org/10.3389/fnins.2017.00604

Holmes EA, O'Connor RC, Perry VH et al (2020) Multidisciplinary research priorities for the COVID-19 pandemic: a call for action for mental health science. The Lancet Psychiatry 7:547-560

Holsboer F (2000) The corticosteroid receptor hypothesis of depression. Neuropsychopharmacology 23:477-501. https://doi.org/10. 1016/S0893-133X(00)00159-7

Huang Y, Zhao N (2020) Generalized anxiety disorder, depressive symptoms and sleep quality during COVID-19 outbreak in China: a web-based cross-sectional survey. Psychiatry Res 288:112954. https://doi.org/10.1016/j.psychres.2020.112954

Iwata M, Ota KT, Duman RS (2013) The inflammasome: pathways linking psychological stress, depression, and systemic illnesses. Brain Behav Immun 31:105-114. https://doi.org/10.1016/j.bbi. 2012.12.008

Jiang H, Wang X, Huang L et al (2011) Benzenediol-berberine hybrids: multifunctional agents for Alzheimer's disease. Bioorg Med Chem 19:7228-7235. https://doi.org/10.1016/j.bmc.2011.09.040

Jiang N, J wei Lv, H xia Wang et al (2019) Antidepressant-like effects of $20(\mathrm{~S})$-protopanaxadiol in a mouse model of chronic social defeat stress and the related mechanisms. Phyther Res 33:27262736. https://doi.org/10.1002/ptr.6446

Joels M, de Kloet E (2017) The brain mineralocorticoid receptor: a saga in three episodes. J Endocrinol 234:T49-T66. https://doi. org/10.1530/JOE-16-0660

Jope R, Cheng Y, Lowell J, et al (2017) Stressed and Inflamed, Can GSK3 Be Blamed? Trends Biochem Sci 42. https://doi.org/10. 1016/j.tibs.2016.10.009

Joseph JJ, Golden SH (2017) Cortisol dysregulation: the bidirectional link between stress, depression, and type 2 diabetes mellitus. Ann N Y Acad Sci 1391:20-34. https://doi.org/10.1111/nyas.13217 
Kaster M, Rosa AO, Santos ARS, et al (2005) Involvement of nitric oxide-cGMP pathway in the antidepressant-like effects of adenosine in the forced swimming test. https://doi.org/10.1017/ S1461145705005316

Kim SH, Oh D-S, Oh JY, et al (2016) Silymarin prevents restraint stress-induced acute liver injury by ameliorating oxidative stress and reducing inflammatory response. Molecules 21 . https://doi.org/10.3390/molecules21040443

Klenerová V, Sída P, Krejcí I et al (2007) Effects of two types of restraint stress on spontaneous behavior of Sprague-Dawley and Lewis rats. J Physiol Pharmacol 58:83-94

Koo JW, Russo SJ, Ferguson D et al (2010) Nuclear factor- $\kappa$ B is a critical mediator of stress-impaired neurogenesis and depressive behavior. Proc Natl Acad Sci 107:2669LP - 2674. https:// doi.org/10.1073/pnas.0910658107

Krajl M (1965) A rapid microfluorimetric determination of monoamine oxidase. Biochem Pharmacol 14:1684-1685. https://doi. org/10.1016/0006-2952(65)90025-0

Kudinova AY, Deak T, Hueston CM et al (2016) Cross-species evidence for the role of interleukin-33 in depression risk. J Abnorm Psychol 125:482-494. https://doi.org/10.1037/abn00 00158

Kulak A, Steullet P, Cabungcal J-H, et al (2013) Redox dysregulation in the pathophysiology of schizophrenia and bipolar disorder: insights from animal models. Antioxid Redox Signal 18. https:// doi.org/10.1089/ars.2012.4858

Kurow O, Frey B, Schuster L et al (2017) Full length interleukin 33 aggravates radiation-induced skin reaction. Front Immunol 8:722. https://doi.org/10.3389/fimmu.2017.00722

Kv A, Madhana RM, JS IC, et al (2018) Antidepressant activity of vorinostat is associated with amelioration of oxidative stress and inflammation in a corticosterone-induced chronic stress model in mice. Behav Brain Res 344:73-84. https://doi.org/10.1016/j. bbr.2018.02.009

Lemos BB, da Motta KP, Paltian JJ et al (2021) Role of 7-chloro-4(phenylselanyl) quinoline in the treatment of oxaliplatin-induced hepatic toxicity in mice. Can J Physiol Pharmacol 99:378-388. https://doi.org/10.1139/cjpp-2020-0134

Li J, Luo Y, Zhang R, et al (2015a) Neuropeptide trefoil factor 3 reverses depressive-like behaviors by activation of BDNF-ERKCREB signaling in olfactory bulbectomized rats. https://doi.org/ 10.3390/ijms 161226105

Li S, Fan Y-X, Wang W, Tang Y-Y (2012) Effects of acute restraint stress on different components of memory as assessed by objectrecognition and object-location tasks in mice. Behav Brain Res 227:199-207. https://doi.org/10.1016/j.bbr.2011.10.007

Li S, Wang Y, Xue J, et al (2020) The impact of COVID-19 epidemic declaration on psychological consequences: a study on active Weibo users. https://doi.org/10.3390/ijerph17062032

Li W, He Q, Wu C et al (2015b) PFOS disturbs BDNF-ERK-CREB signalling in association with increased MicroRNA-22 in SHSY5Y cells. Biomed Res Int 2015:302653. https://doi.org/10. $1155 / 2015 / 302653$

Li X, Su L, Zhang X et al (2017) Ulinastatin downregulates TLR4 and $\mathrm{NF}-\mathrm{kB}$ expression and protects mouse brains against ischemia/ reperfusion injury. Neurol Res 39:1-7. https://doi.org/10.1080/ 01616412.2017 .1286541

Linthorst ACE, Reul JM (2008) Stress and the brain: solving the puzzle using microdialysis. Pharmacol Biochem Behav 90:163-173

Liu L, Wang Y, Yu Q (2014) The PI3K/Akt signaling pathway exerts effects on the implantation of mouse embryos by regulating the expression of RhoA. Int J Mol Med 33. https://doi.org/10.3892/ ijmm.2014.1701

Livak KJ, Schmittgen TD (2001) Analysis of relative gene expression data using real-time quantitative PCR and the 2- $\Delta \Delta \mathrm{CT}$ method. Methods 25:402-408. https://doi.org/10.1006/meth.2001.1262
Loetchutinat C, Kothan S, Dechsupa S et al (2005) Spectrofluorometric determination of intracellular levels of reactive oxygen species in drug-sensitive and drug-resistant cancer cells using the 2',7'-dichlorofluorescein diacetate assay. Radiat Phys Chem 72:323-331. https://doi.org/10.1016/j.radphyschem.2004.06.011

Lowy MT, Reder AT, Antel JP, MHY, (1984) Glucocorticoid resistance in depression: the dexamethasone suppression test and lymphocyte sensitivity to dexamethasone. Am J Psychiatry 141:13651370. https://doi.org/10.1176/ajp.141.11.1365

Lu C, Dong L, Lv J, et al (2018) 20(S)-protopanaxadiol (PPD) alleviates scopolamine-induced memory impairment via regulation of cholinergic and antioxidant systems, and expression of Egr-1, c-Fos and c-Jun in mice. Chem Biol Interact 279. https://doi.org/ 10.1016/j.cbi.2017.11.008

Luchese C, Barth A, da Costa GP et al (2020) Role of 7-chloro-4(phenylselanyl) quinoline as an anti-aging drug fighting oxidative damage in different tissues of aged rats. Exp Gerontol 130:110804. https://doi.org/10.1016/j.exger.2019.110804

Lueptow LM (2017) Novel object recognition test for the investigation of learning and memory in mice. J Vis Exp 55718. https://doi. org/10.3791/55718

Lupien SJ, McEwen BS, Gunnar MR, Heim C (2009) Effects of stress throughout the lifespan on the brain, behaviour and cognition. Nat Rev Neurosci 10:434-445. https://doi.org/10.1038/nrn2639

Maes M, Kubera M, Obuchowicz E et al (2011) Depression's multiple comorbidities explained by (neuro)inflammatory and oxidative \& nitrosative stress pathways. Neuro Endocrinol Lett 32:7-24

Mancino AM, Hindo SS, Kochi A, Lim MH (2009) Effects of clioquinol on metal-triggered amyloid- $\beta$ aggregation revisited. Inorg Chem 48:9596-9598. https://doi.org/10.1021/ic9014256

Marazziti D, Consoli G, Picchetti M et al (2010) Cognitive impairment in major depression. Eur J Pharmacol 626:83-86

Mariotti A (2015) The effects of chronic stress on health: new insights into the molecular mechanisms of brain-body communication. Futur Sci OA 1:null. https://doi.org/10.4155/fso.15.21

Martini F, Rosa SG, Klann IP et al (2019) A multifunctional compound ebselen reverses memory impairment, apoptosis and oxidative stress in a mouse model of sporadic Alzheimer's disease. J Psychiatr Res 109:107-117. https://doi.org/10.1016/j.jpsychires. 2018.11.021

Mcewen BS, Gianaros PJ (2010) Central role of the brain in stress and adaptation: Links to socioeconomic status, health, and disease. Ann NY Acad Sci 1186:190-222. https://doi.org/10.1111/j.17496632.2009.05331.x

Miller AH, Maletic V, Raison CL (2009) Inflammation and its discontents: the role of cytokines in the pathophysiology of major depression. Biol Psychiatry 65:732-741. https://doi.org/10. 1016/j.biopsych.2008.11.029

Miret M, Ayuso-Mateos JL, Sanchez-Moreno J, Vieta E (2013) Depressive disorders and suicide: epidemiology, risk factors, and burden. Neurosci Biobehav Rev 37:2372-2374

Misra HP, Fridovich I (1972) The role of superoxide anion in the autoxidation of epinephrine and a simple assay for superoxide dismutase. J Biol Chem 247:3170-3175

Moretti M, Budni J, dos Santos DB et al (2013) Protective effects of ascorbic acid on behavior and oxidative status of restraintstressed mice. J Mol Neurosci 49:68-79. https://doi.org/10.1007/ s12031-012-9892-4

Mosaffa S, Ahmadi H, Khakpai F et al (2021) Synergistic antidepressant- and anxiolytic-like effects of harmaline along with cinanserin in acute restraint stress-treated mice. Psychopharmacology 238:259-269. https://doi.org/10.1007/s00213-020-05679-6

Murrough JW, Iacoviello B, Neumeister A et al (2011) Cognitive dysfunction in depression: neurocircuitry and new therapeutic strategies. Neurobiol Learn Mem 96:553-563. https://doi.org/ 10.1016/j.nlm.2011.06.006 
Nagata K, Nakashima-Kamimura N, Mikami T et al (2009) Consumption of molecular hydrogen prevents the stress-induced impairments in hippocampus-dependent learning tasks during chronic physical restraint in mice. Neuropsychopharmacology 34:501-508. https://doi.org/10.1038/npp.2008.95

Niksiyar AH, Meftahi GH, Sahraei H (2021) The effect of continuous stress on spatial learning and memory, anxiety-like behavior, and depression in male NMRI mice. Proc Natl Acad Sci India Sect B Biol Sci 91:21-28. https://doi.org/10.1007/ s40011-020-01198-8

O'Neill LAJ, Kaltschmidt C (1997) NF-кB: A crucial transcription factor for glial and neuronal cell function. Trends Neurosci 20:252-258. https://doi.org/10.1016/S0166-2236(96)01035-1

Oeckinghaus A, Ghosh S (2009) The NF-kB family of transcription factors and its regulation. cold spring Harb Perspect Biol 4:a000034. https://doi.org/10.1101/cshperspect.a000034

Ohkawa H, Ohishi N, Yagi K (1979) Assay for lipid peroxides in animal tissues by thiobarbituric acid reaction. Anal Biochem 95:351-358. https://doi.org/10.1016/0003-2697(79)90738-3

Otte C, Gold SM, Penninx BW et al (2016) Major depressive disorder. Nat Rev Dis Prim 2:16065. https://doi.org/10.1038/nrdp.2016.65

Oz M, Lorke DE, Petroianu GA (2009) Methylene blue and Alzheimer's disease. Biochem Pharmacol 78:927-932. https://doi.org/ 10.1016/j.bcp.2009.04.034

Paltian JJ, dos Reis AS, de Oliveira RL et al (2020) The anxiolytic effect of a promising quinoline containing selenium with the contribution of the serotonergic and GABAergic pathways: modulation of parameters associated with anxiety in mice. Behav Brain Res 393:112797. https://doi.org/10.1016/j.bbr.2020.112797

Parasuraman S, Raveendran R, Kesavan R (2010) Blood sample collection in small laboratory animals. J Pharmacol Pharmacother 1:87-93. https://doi.org/10.4103/0976-500X.72350

Pesarico AP, Stangherlin EC, Mantovani AC et al (2015) 7-Fluoro1,3-diphenylisoquinoline-1-amine abolishes depressive-like behavior and prefrontal cortical oxidative damage induced by acute restraint stress in mice. Physiol Behav 149:294-302. https://doi.org/10.1016/j.physbeh.2015.06.018

Pinz M, Reis AS, Duarte V et al (2016) 4-Phenylselenyl-7-chloroquinoline, a new quinoline derivative containing selenium, has potential antinociceptive and anti-inflammatory actions. Eur J Pharmacol 780:122-128. https://doi.org/10.1016/j.ejphar.2016.03.039

Pinz MP, dos Reis AS, Vogt AG et al (2018) Current advances of pharmacological properties of 7-chloro-4-(phenylselanyl) quinoline: prevention of cognitive deficit and anxiety in Alzheimer's disease model. Biomed Pharmacother 105:1006-1014. https://doi.org/10. 1016/j.biopha.2018.06.049

Porsolt RD, Le Pichon M, Jalfre M (1977) Depression: a new animal model sensitive to antidepressant treatments. Nature 266:730732. https://doi.org/10.1038/266730a0

Pregardier Klann I, Martini F, Rosa S, Nogueira C (2020) Ebselen reversed peripheral oxidative stress induced by a mouse model of sporadic Alzheimer's disease. Mol Biol Rep 47. https://doi. org/10.1007/s11033-020-05326-5

Qi D-S, Tao J, Zhang L-Q, et al (2016) Neuroprotection of Cilostazol against ischemia/reperfusion-induced cognitive deficits through inhibiting JNK3/caspase-3 by enhancing Akt1. Brain Res 1653. https://doi.org/10.1016/j.brainres.2016.10.017

Reis AS, Pinz M, Duarte LFB et al (2017) 4-phenylselenyl-7-chloroquinoline, a novel multitarget compound with anxiolytic activity: contribution of the glutamatergic system. J Psychiatr Res 84:191-199. https://doi.org/10.1016/j.jpsychires.2016.10.007

Rodrigues KC, Bortolatto CF, da Motta KP, de Oliveira RL, Paltian JJ, Krüger R, Roman SS, Boeira SP, Alves D, Wilhelm EALC (2021) The neurotherapeutic role of a selenium-functionalized quinoline in hypothalamic obese rats. Psychopharmacology. https://doi.org/10.1007/s00213-021-05821
Romano A, Pace L, Tempesta B, et al (2015) Depressive-like behavior is paired to monoaminergic alteration in a murine model of Alzheimer's disease (Drs Serviddio and Vendemiale). Int J Neuropsychopharmacol 1-12. https://doi.org/10.1093/ijnp/pyu020

Salgueiro WG, Goldani BS, Peres TV et al (2017) Insights into the differential toxicological and antioxidant effects of 4-phenylchalcogenil-7-chloroquinolines in Caenorhabditis elegans. Free Radic Biol Med 110:133-141. https://doi.org/10.1016/j.freeradbiomed. 2017.05.020

Sarter M, Bodewitz G, Stephens DN (1988) Attenuation of scopolamine-induced impairment of spontaneous alternation behaviour by antagonist but not inverse agonist and agonist $\beta$-carbolines. Psychopharmacology 94:491-495. https://doi.org/10.1007/ BF00212843

Saura J, Luque JM, Cesura AM et al (1994) Increased monoamine oxidase $\mathrm{b}$ activity in plaque-associated astrocytes of Alzheimer brains revealed by quantitative enzyme radioautography. Neuroscience 62:15-30. https://doi.org/10.1016/0306-4522(94) 90311-5

Sher L (2000) Selenium and human health. Lancet 356:943. https://doi. org/10.1016/S0140-6736(05)73927-1

Shih JC, Chen K, Ridd MJ (1999) Monoamine oxidase: from genes to behavior. Annu Rev Neurosci 22:197-217. https://doi.org/10. 1146/annurev.neuro.22.1.197

Shiota N, Narikiyo K, Masuda A, Aou S (2016) Water spray-induced grooming is negatively correlated with depressive behavior in the forced swimming test in rats. J Physiol Sci 66:265-273. https:// doi.org/10.1007/s12576-015-0424-1

Sierksma ASR, van den Hove DLA, Steinbusch HWM, Prickaerts J (2010) Major depression, cognitive dysfunction and Alzheimer's disease: is there a link? Eur J Pharmacol 626:72-82

Silva V, Reis A, Pinz M, et al (2017) Further analysis of acute antinociceptive and anti-inflammatory actions of 4-phenylselenyl7-chloroquinoline in mice. Fundam Clin Pharmacol 31. https:// doi.org/10.1111/fcp. 12295

Silverman HA, Dancho M, Regnier-Golanov A et al (2015) Brain region-specific alterations in the gene expression of cytokines, immune cell markers and cholinergic system components during peripheral endotoxin-induced inflammation. Mol Med 20:601611. https://doi.org/10.2119/molmed.2014.00147

Siomek A (2012) NF-кB signaling pathway and free radical impact. Acta Biochim Pol 59:323-331. https://doi.org/10.18388/abp. 2012_2116

Sousa F, Taborda Birmann P, Balaguez R, et al (2018) $\alpha$-(phenylselanyl) acetophenone abolishes acute restraint stress induced-comorbid pain, depression and anxiety-related behaviors in mice. Neurochem Int 120. https://doi.org/10.1016/j.neuint.2018.08.006

Steru L, Chermat R, Thierry B, Simon P (1985) The tail suspension test: a new method for screening antidepressants in mice. Psychopharmacology 85:367-370. https://doi.org/10.1007/BF004 28203

Van Erp AMM, Kruk MR, Meelis W, Willekens-Bramer DC (1994) Effect of environmental stressors on time course, variability and form of self-grooming in the rat: handling, social contact, defeat, novelty, restraint and fur moistening. Behav Brain Res 65:47-55. https://doi.org/10.1016/0166-4328(94)90072-8

Varikasuvu SR, Prasad VS, Kothapalli J, Manne M (2019) Brain selenium in Alzheimer's disease (BRAIN SEAD Study): a systematic review and meta-analysis. Biol Trace Elem Res 189:361-369. https://doi.org/10.1007/s12011-018-1492-x

Vasconcelos A, Oliveira I, Vidal L, et al (2015) Subchronic administration of riparin III induces antidepressive-like effects and increases BDNF levels in the mouse hippocampus. Fundam Clin Pharmacol 29. https://doi.org/10.1111/fcp.12120

Vermeiren Y, Van Dam D, Aerts T et al (2014) Monoaminergic neurotransmitter alterations in postmortem brain regions of depressed 
and aggressive patients with Alzheimer's disease. Neurobiol Aging 35:2691-2700. https://doi.org/10.1016/j.neurobiolaging. 2014.05.031

Vogt AG, Voss GT, de Oliveira RL et al (2018) Organoselenium group is critical for antioxidant activity of 7-chloro-4-phenylselenylquinoline. Chem Biol Interact 282:7-12. https://doi.org/10. 1016/j.cbi.2018.01.003

Walesiuk A, Trofimiuk E, Braszko J (2005) Ginkgo biloba extract diminishes stress-induced memory deficits in rats. Pharmacol Rep 57:176-187

Walsh RN, Cummins RA (1976) The open-field test: a critical review. Psychol Bull 83:482-504

Wang J, Um P, Dickerman BA, Liu J (2018) Zinc, magnesium, selenium and depression: a review of the evidence, potential mechanisms and implications. Nutrients 10:584. https://doi.org/10. 3390/nu10050584

Wendel A (1981) Glutathione peroxidase. Methods Enzymol 77:325333. https://doi.org/10.1016/S0076-6879(81)77046-0

Wolf O (2008) The influence of stress hormones on emotional memory: relevance for psychopathology. Acta Psychol (amst) 127:513531. https://doi.org/10.1016/j.actpsy.2007.08.002
World Health Organization (2021) Depression. https://www.who.int/ en/news-room/fact-sheets/detail/depression. Accessed $20 \mathrm{Jan}$ 2003

Xiong J, Lipsitz O, Nasri F et al (2020) Impact of COVID-19 pandemic on mental health in the general population: a systematic review. J Affect Disord 277:55-64

Yang PC, Yang CH, Huang CC, Sen HK (2008) Phosphatidylinositol 3-kinase activation is required for stress protocol-induced modification of hippocampal synaptic plasticity. J Biol Chem 283:2631-2643. https://doi.org/10.1074/jbc.M706954200

Zenker N, Bernstein DE (1958) The estimation of small amounts of corticosterone in rat plasma. J Biol Chem 231:695-701. https:// doi.org/10.1016/s0021-9258(18)70434-1

Publisher's note Springer Nature remains neutral with regard to jurisdictional claims in published maps and institutional affiliations. 